\title{
Descriptive and functional characterization of epidermal growth factor-like domain 8 in mouse cortical thymic epithelial cells by integrated analysis of gene expression signatures and networks
}

\author{
YE SEON LIM ${ }^{1,2}$, DO-YOUNG LEE ${ }^{1,2}$, HYE-YOON KIM ${ }^{1,2}$, YEJIN OK $^{1,2}$,

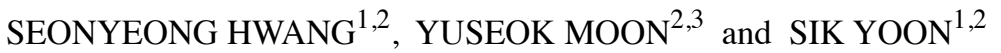

\begin{abstract}
${ }^{1}$ Department of Anatomy, Pusan National University School of Medicine; ${ }^{2}$ Immune Reconstitution Research Center, Medical Research Institute, Pusan National University School of Medicine; ${ }^{3}$ Department of Biomedical Sciences, Pusan National University School of Medicine, Yangsan, Gyeongsangnam-do 50612, Republic of Korea
\end{abstract}

Received February 14, 2019; Accepted November 24, 2020

DOI: $10.3892 / \mathrm{ijmm} .2020 .4837$

\begin{abstract}
Epidermal growth factor-like domain 8 (EGFL8), a newly identified member of the EGFL family, and plays negative regulatory roles in mouse thymic epithelial cells (TECs) and thymocytes. However, the role of EGFL8 in these cells remains poorly understood. In the present study, in order to characterize the function of EGFL8, genome-wide expression profiles in EGFL8-overexpressing or -silenced mouse cortical TECs (cTECs) were analyzed. Microarray analysis revealed that 458 genes exhibited a $>2$-fold change in expression levels in the EGFL8-overexpressing vs. the EGFL8-silenced cTECs. Several genes involved in a number of cellular processes, such as the cell cycle, proliferation, growth, migration and differentiation, as well as in apoptosis, reactive oxygen species generation, chemotaxis and immune responses, were differentially expressed in the EGFL8-overexpressing or -silenced cTECs. WST-1 analysis revealed that that the overexpression of EGFL8 inhibited cTEC proliferation. To investigate the underlying mechanisms of EGFL8 in the regulation of cTEC function, genes related to essential cellular functions were selected. Reverse transcription-polymerase chain reaction analysis revealed that EGFL8 knockdown upregulated the expression of cluster differentiation 74 (CD74), Fas ligand (FasL), C-X-C motif chemokine ligand 5 (CXCL5), CXCL10, CXCL16, C-C motif chemokine ligand 20 (CCL20), vascular endothelial growth factor-A (VEGF-A), interferon regulatory factor 7 (Irf7), insulin-like growth factor binding protein-4 (IGFBP-4), thrombospondin 1 (Thbs1) and nuclear factor $\kappa \mathrm{B}$ subunit $2(\mathrm{NF}-\kappa \mathrm{B} 2)$ genes, and downregulated the expression
\end{abstract}

Correspondence to: Professor Sik Yoon, Department of Anatomy, Pusan National University School of Medicine, 49 Busandaehak-ro, Yangsan, Gyeongsangnam-do 50612, Republic of Korea E-mail: sikyoon@pusan.ac.kr

Key words: epidermal growth factor-like domain 8, gene expression, gene network, microarray, cortical thymic epithelial cells of angiopoietin-like 1 (Angptl1), and neuropilin-1 (Nrp1) genes. Additionally, EGFL8 silencing enhanced the expression of anti-apoptotic molecules, such as B-cell lymphoma-2 (Bcl-2) and Bcl-extra large (Bcl-xL), and that of cell cycle-regulating molecules, such as cyclin-dependent kinase 1 (CDK1), CDK4, CDK6 and cyclin D1. Moreover, gene network analysis revealed that EGFL8 exerted negative effects on VEGF-A gene expression. Hence, the altered expression of several genes associated with EGFL8 expression in cTECs highlights the important physiological processes in which EGFL8 is involved, and provides insight into its biological functions.

\section{Introduction}

Thymic epithelial cells (TECs) are key components of the thymic stromal compartment, which creates a specialized microenvironment for the maturation of $\mathrm{T}$ cell precursors into mature, immunocompetent cells at various stages of development. TECs are closely associated with developing thymocytes within the thymic microenvironment, playing a crucial role in the attraction, migration, survival, proliferation, differentiation and the selection of thymocytes (1). Histologically, the thymus can be divided into two sub-compartments, the outer cortex and the inner medulla, which hold different populations of TECs and thymocytes undergoing discrete, stepwise maturation. TECs are largely composed of the cortical and medullary types, and serial interactions of TECs with thymocytes, including positive and negative selection of the $\mathrm{T}$ cell repertoire, are required for thymocyte development (2).

The age-related involution of the thymus, a major cause of the decreased production of $\mathrm{T}$ cells and the subsequent loss of immune function in the elderly, is closely associated with aging of TECs, which is linked to various mechanisms, such as the inhibition of thymopoietic cytokine production (3). Furthermore, TECs play a pivotal role in thymic regeneration. In particular, multiple lines of evidence have indicated that cortical TECs (cTECs) play a key role in the regeneration process of the damaged thymus by producing a variety of factors (4-9). However, the molecular mechanisms underlying thymus regeneration remain largely unknown, although some 
molecules, including interleukin (IL)-7, keratinocyte growth factor, transforming growth factor- $\beta$ (TGF- $\beta$ ), insulin-like growth factor-1 (IGF-1), Wnt-4 and IL-22 have been identified thus far $(10,11)$. An enhanced understanding of the process of thymopoietic regulation at a molecular level, particularly the molecular basis of TEC function, is essential for the development and maintenance of a healthy, intact immune system. Therefore, an effective approach is required to identify positive or negative regulatory factors involved in TEC functioning that may aid in developing innovative therapeutic strategies to promote thymus regeneration, which may ultimately lead to the successful treatment of a number of clinical conditions caused by $\mathrm{T}$ cell deficiency.

Epidermal growth factor-like domain (EGFL), consisting of 30-40 amino acid residues possessing significant homology to epidermal growth factor (EGF), is an evolutionarily conserved domain present in many vertebrate proteins (12-15). EGFL proteins, characterized by the presence of single or multiple EGFL repeats, are membrane-bound or secreted, and function in several essential cellular activities, such as cell proliferation, differentiation, apoptosis, adhesion, and migration $(16,17)$. Several EGFL family members have been identified, including EGFL2, EGFL3, EGFL5, EGFL6, EGFL7, EGFL8, and EGFL9. Among these, EGFL2, EGFL5 and EGFL9 contain transmembrane domains, whereas EGFL3, EGFL6, EGFL7 and EGFL8 lack these domains, and are secreted into the extracellular environment $(17,18)$.

EGFL8, a newly identified member of the EGFL family, was originally identified as a paralog of EGFL7 using a Basic Local Alignment Search Tool (BLAST) of the mouse genome (19). The expression of EGFL8 has been detected in osteoclasts and osteoblasts (18). Additionally, it has been reported that the EGFL8 expression level is significantly decreased in colorectal and gastric cancer, suggesting that EGFL8 may have a distinct expression pattern and mechanism of action in cancer progression $(20,21)$. Recently, it has been demonstrated that EGFL8 is expressed during T cell development in both TECs and thymocytes and is involved in the suppression of thymocyte differentiation $(22,23)$. Additionally, the overexpression of EGFL8 may exert negative regulatory effects on TECs through the inhibition of thymocyte adherence to TECs and the suppression of the expression of molecules involved in TEC function (22). This finding may facilitate the development of therapeutic strategies for the treatment of immune-mediated diseases associated with $\mathrm{T}$ cell abnormalities. However, the precise cellular functions of EGFL8 are not fully understood. A high throughput study may be the most effective, available approach to characterize global changes in gene expression to create an overall picture of cellular function. Therefore, the aim of the present study was to identify novel EGFL8 targets among the induced differentially expressed genes (DEGs), and to discover molecular interaction networks underlying the global effects of EGFL8 using an integrated analysis of gene expression profiles and networks in EGFL8-overexpressing or -silenced cTECs. It is reported herein that EGFL8 is likely to be involved in the regulation of the cell cycle, cell proliferation, differentiation, apoptosis and migration, as well as in immune responses, and may also be an important regulator of vascular endothelial growth factor-A (VEGF-A) gene expression.

\section{Materials and methods}

Cell lines and cell culture. The generation, maintenance and functional characterization of 427.1 mouse cTECs, which represent mouse thymic sub-capsular cortex or thymic nurse epithelial cells, were performed as described previously (24), and the cells were kindly provided by The Jackson Laboratory. These cell lines constitutively express the class I antigens of the major histocompatibility complex (MHC), and can be induced to express MHC class II antigens upon stimulation with recombinant interferon (IFN) $-\gamma$ and produce granulocyte-macrophage colony-stimulating factor (GM-CSF) (24). cTECs were cultured and maintained in high-glucose Dulbecco's modified Eagle's medium (DMEM; Gibco; Thermo Fisher Scientific, Inc.) containing 10\% fetal bovine serum (FBS; Gibco; Thermo Fisher Scientific, Inc.), 2 mM glutamine (Sigma-Aldrich; Merck KGaA), $100 \mathrm{U} / \mathrm{ml}$ penicillin (Gibco; Thermo Fisher Scientific, Inc.), and $100 \mu \mathrm{g} / \mathrm{ml}$ streptomycin (Gibco; Thermo Fisher Scientific, Inc.) at $37^{\circ} \mathrm{C}$ in a $5 \% \mathrm{CO}_{2}$-enriched atmosphere.

Plasmid constructs and transfection. To construct EGFL8 plasmids, full-length mouse EGFL8 complementary DNA (cDNA) was amplified with total thymic RNA using polymerase chain reaction (PCR) with $B a m \mathrm{HI}$ and $\mathrm{XbaI}$ restriction enzymes, and cloned into a pcDNA3.1 mammalian expression vector (Life Technologies; Thermo Fisher Scientific, Inc.). The PCR-amplified DNA sequence was analyzed by Bionics Co. Ltd., and the presence of any errors in the PCR product, such as point mutations, deletions, insertions and duplications was not detected (data not shown). The cTECs were transfected with $5 \mu \mathrm{g}$ pcDNA3.1-EGFL8 expression constructs using Lipofectamine 2000 reagent (Gibco; Thermo Fisher Scientific, Inc.) according to the manufacturer's instructions. The media were changed after 4-6 h to antibiotic-containing media and incubated at $37^{\circ} \mathrm{C}$ for a further $48 \mathrm{~h}$.

To construct mouse EGFL8 gene knockdowns, siRNA duplex oligos and scrambled control siRNA with an overhang of dTdT were synthesized by Bioneer Corp. The siRNA sequences for mouse EGFL8 were as follows: 5'-CCAGAG GAGGAUCUUUCAA-3' (siRNA1), 5'-GGAUCUUUCAAA GAGAGUU-3' (siRNA2). The cTECs were seeded into 6-well microplates or a $100 \mathrm{~mm}$ dish and transfected with $100 \mathrm{pmol}$ of siRNA using Lipofectamine ${ }^{\mathrm{TM}} 2000$ reagent according to the manufacturer's instructions. The media were changed after 4-6 $\mathrm{h}$ to antibiotic-containing media and incubated at $37^{\circ} \mathrm{C}$; the cTECs were harvested 2 days following siRNA transfection, and EGFL8 knockdown efficiency was confirmed by RT-PCR.

Gene microarray and expression analysis. The effects of the overexpression or knockdown of the mouse EGFL8 gene in cTECs on whole genome expression profiles were investigated using a whole transcript genechip microarray (GeneChip ${ }^{\circledR}$ Mouse Gene 1.0 ST Array; Affymetrix; Thermo Fisher Scientific, Inc.), which has 770,317 distinct 25-mer oligonucleotide probes that represent 28,853 well-annotated mouse genes. Total RNA for microarray analysis was isolated using the RNeasy Mini kit as per the manufacturer's instructions and recommendations (Qiagen, Inc.). Briefly, cells were diced in a mixture of $1.5 \mathrm{ml}$ QG buffer (Qiagen, Inc.) 
and $2 \mathrm{ml}$ RLT buffer (Qiagen, Inc.). Samples were kept at room temperature until complete dissolution and then stored at $-20^{\circ} \mathrm{C}$. Defrosted samples were homogenized and supplemented with $2 \mathrm{ml} \mathrm{70 \%} \mathrm{ethanol.} \mathrm{RNA} \mathrm{quality} \mathrm{was} \mathrm{assessed}$ using Agilent 2100 Bioanalyzer (Agilent Technologies, Inc.) with the RNA 6000 Nano Chip (Agilent Technologies, Inc.), and quantified using a Nanodrop 2000 Spectrophotometer (Thermo Fisher Scientific, Inc.). Biological triplicates were obtained for each group: Mock pcDNA3.1-vector-transfected cTECs, pcDNA3.1-EGFL8-transfected cTECs, scrambled siRNA-transfected cTECs, and EGFL8 siRNA-transfected cTECs. The labeling and hybridization of total RNA were performed by DNALink Incorporated (Affymetrix-authorized service provider), according to the standard protocol. Global gene expression analysis for each sample was performed using GeneChip ${ }^{\circledR}$ Mouse Gene 1.0 ST Arrays (Affymetrix; Thermo Fisher Scientific, Inc.) as per the recommended manufacturer's protocols. Briefly, $300 \mathrm{ng}$ of total RNA from each sample was converted to double-stranded cDNA. Using a random hexamer incorporating a T7 promoter, amplified RNA (cRNA) was generated from the double-stranded cDNA template though an in vitro transcription reaction and purified with the Affymetrix sample cleanup module. cDNA was regenerated through a random-primed reverse transcription using a deoxynucleotide triphosphate (dNTP) mixture containing deoxyuridine triphosphate (dUTP) (Promega Corporation). The cDNA was then fragmented by uracil-DNA glycosylase (UDG) and human apurinic/apyrimidinic endonuclease-1 (APE1, also known as HAP1, REF1 and APEX1) and end-labeled using a terminal transferase reaction incorporating a biotinylated dideoxynucleotide (ddNTP). Fragmented end-labeled cDNA was hybridized to the GeneChip ${ }^{\circledR}$ Mouse Gene 1.0 ST arrays for $17 \mathrm{~h}$ at $45^{\circ} \mathrm{C}$ and $60 \mathrm{rpm}$ as described in the Gene Chip Whole Transcript Sense Target Labeling Assay Manual (Affymetrix; Thermo Fisher Scientific, Inc.).

Following hybridization, the microarrays were passed through a wash process and marking was performed by streptavidin-phycoerythrin using the 'GeneChip Fluidics Station 450' (Affymetrix; Thermo Fisher Scientific, Inc.). Subsequently, the microarrays were scanned with 'GeneChip Scanner 3000 7G' (Affymetrix; Thermo Fisher Scientific, Inc.) and images of each sample were obtained. The quality control of these images was performed using the program 'Affymetrix GeneChip Command Console'. Each hybridization was a distinct biological replicate.

Cell proliferation assay. The cTECs were plated into 96-well microplates at $3 \times 10^{4}$ cells/well in DMEM containing $10 \%$ FBS. The cells were left untreated as an untreated control, or transfected with either $5 \mu \mathrm{g}$ pcDNA3.1-EGFL8 or 100 pmol EGFL8 siRNA2 in antibiotic-free medium using Lipofectamine $^{\mathrm{TM}} 2000$ (Gibco; Thermo Fisher Scientific, Inc.). A rescue experiment was also performed by co-transfection with EGFL8 siRNA2 and pcDNA3.1-EGFL8. After the cells were cultured for $48 \mathrm{~h}$, cell proliferation was determined using the colorimetric WST-1 conversion assay (EZ-Cytox assay kit; Daeil Lab Service). WST-1 reagent (10 $\mu \mathrm{l})$ was added to each well, after which the cells were incubated for $2 \mathrm{~h}$ at $37^{\circ} \mathrm{C}$ in a humidified atmosphere under $5 \% \mathrm{CO}_{2}$. The absorbance of the formazan dye, generated by the reaction between dehydrogenase and WST-1 in metabolically active cells, was measured using a microplate reader (Tecan Group Ltd.) at $450 \mathrm{~nm}$ according to the manufacturer's instructions. The percentage cell viability was calculated. Experiments were performed a minimum of 3 times.

$R T-P C R$. Total RNA was isolated from the cultured cells using TRIzol reagent (Gibco; Thermo Fisher Scientific, Inc.) following the manufacturer's instructions. The RNA quantity and quality were assessed using a NanoDrop 2000 spectrophotometer (Thermo Fisher Scientific, Inc.). Briefly, the samples were transferred into RNA extraction solution $(1 \mathrm{ml})$. The homogenate was then chloroform-extracted, precipitated with isopropanol, washed with ethanol and resuspended in $30 \mu \mathrm{l}$ of distilled water. The RNA concentration and purity were determined by measuring the absorbance at 260 and $280 \mathrm{~nm}$. Samples exhibited 260/280 absorbance ratios $\geq 1$.9. First-strand cDNA synthesis was performed by reverse transcription using total RNA $(2 \mu \mathrm{g})$. The reaction was conducted in a $25 \mu \mathrm{l}$ reaction mixture containing $0.5 \mu \mathrm{g}$ oligo(dT) $12-18$ primer (Promega Corporation), $50 \mathrm{mM}$ Tris- $\mathrm{HCl}$ (pH 8.3), $75 \mathrm{mM} \mathrm{KCl}$, $3 \mathrm{mM} \mathrm{MgCl}_{2}, 40 \mathrm{mM}$ dithiothreitol, $0.5 \mathrm{mM}$ dNTP mixture (Promega Corporation), 10 units RNase inhibitor (Promega Corporation) and 200 units of Moloney murine leukemia virus reverse transcriptase (Promega Corporation). The mixture was incubated at $37^{\circ} \mathrm{C}$ for $60 \mathrm{~min}$, and the reaction was terminated by heating at $70^{\circ} \mathrm{C}$ for $5 \mathrm{~min}$. The obtained cDNA was used as a template for PCR amplification using gene-specific primers. The primer sequences are presented in Table I. The PCR amplification of cDNA was performed in an automated thermal cycler (PC-320, Astec, Co. Ltd.) in a final reaction volume of $25 \mu \mathrm{l}$ containing the following components: $4 \mu \mathrm{l}$ of cDNA solution, $20 \mathrm{mM}$ Tris- $\mathrm{HCl}(\mathrm{pH} \mathrm{8.4),} 50 \mathrm{mM} \mathrm{KCl}$, $1.5 \mathrm{mM} \mathrm{MgCl}{ }_{2}, 0.1 \%$ Triton X-100, $0.2 \mathrm{mM}$ dNTP mixture (Promega Corporation), 0.5 pmol of each primer and 5 units of Taq DNA polymerase (Promega Corporation). All PCR reactions were performed in 22 to 35 cycles at $94^{\circ} \mathrm{C}$ for $30 \mathrm{sec}$, $55^{\circ} \mathrm{C}$ for $30 \mathrm{sec}$, and $72^{\circ} \mathrm{C}$ for $30 \mathrm{sec}$. Amplified products were analyzed by electrophoresis using a $2 \%$ agarose gel and visualized by ethidium bromide staining under ultraviolet light. The band intensities of PCR products were quantified and analyzed using an image analysis software (ImageJ, version 1.52a, National Institute of Health). The results are expressed as ratios vs. glyceraldehyde-3-phosphate dehydrogenase (GAPDH) mRNA amplified from the same cDNA samples.

Western blot analysis. The cells were cultured in $100 \mathrm{~mm}$ dishes overnight and incubated at $37^{\circ} \mathrm{C}$ in a $5 \% \mathrm{CO}_{2}$-enriched atmosphere with siRNA in antibiotic-free media according to the manufacturer's protocol for Lipofectamine ${ }^{\mathrm{TM}} 2000$ (Gibco; Thermo Fisher Scientific, Inc.). The media were changed after 4-6 h to antibiotic-containing media and incubated at $37^{\circ} \mathrm{C}$ for a further $48 \mathrm{~h}$. The total proteins were extracted from the cultured cells using a protein extraction solution (Intron Biotechnology, Inc.) supplemented with protease inhibitor mixture (Roche Applied Science). Protein concentrations were measured using the Bradford protein assay kit (Bio-Rad Laboratories, Inc.). A total of $25 \mu \mathrm{g}$ of equal protein from each sample was electrophoresed by sodium dodecyl sulfate-polyacrylamide gel electrophoresis (SDS-PAGE) on a $8-12 \%(\mathrm{v} / \mathrm{v})$ 
Table I. Primer sequences used for RT-PCR in the present study.

\begin{tabular}{lll}
\hline Target gene & \multicolumn{1}{c}{ Forward primer sequence } & \multicolumn{1}{c}{ Reverse primer sequence } \\
\hline Angpt1 & ATCCCGACTTGAAATACAACTGC & CTGGATGATGAATGTCTGACGAG \\
CCL20 & CGACTGTTGCCTCTCGTACA & GAGGAGGTTCACAGCCCTTT \\
CD74 & CGCGACCTCATCTCTAACCAT & ACAGGTTTGGCAGATTTCGGA \\
CXCL5 & GCATTTCTGTTGCTGTTCACGCTG & CCTCCTTCTGGTTTTCAGTTAGC \\
CXCL10 & CCAAGTGCTGCCGTCATTTTC & GGCTCGCAGGGATGATTCAA \\
CXCL16 & CCTTGTCTCTTGCGTTCTTCC & TCCAAAGTACCCTGCGGTATC \\
FasL & TATCAAGGAGGCCCATTTTGC & GTTTCCACTTCTAAACCATGCT \\
IGFBP-4 & CAGCGTGCTTGCTAACTTCC & TAGAGAACCAGACCCGGAGG \\
Irf7 & TGCTGTTTGGAGACTGGCTAT & TCCAAGCTCCCGGCTAAGT \\
NF-kB2 & GGCCGGAAGACCTATCCTACT & CTACAGACACAGCGCACACT \\
Nrp1 & TGTAAGCTCGGAAGGGCATC & TAACGCCTAGTGCCAGCATC \\
Thbs1 & GCTGCCAATCATAACCAGCG & GGTTGTTTGGCGGTGAGTTC \\
VEGF-A & GCACATAGAGAGAATGAGCTTCC & CTCCGCTCTGAACAAGGCT \\
GAPDH & ACCACAGTCCATGCCATCAC & GGCTACAGCAACAGGGTGGTG
\end{tabular}

Angptl1, angiopoietin-like 1; CCL20, chemokine (C-C motif) ligand 20; CD74, cluster differentiation 74; CXCL5, C-X-C motif chemokine ligand 5; CXCL10, C-X-C motif chemokine ligand 10; CXCL16, C-X-C motif chemokine ligand 16, FasL, Fas ligand; IGFBP-4, insulin

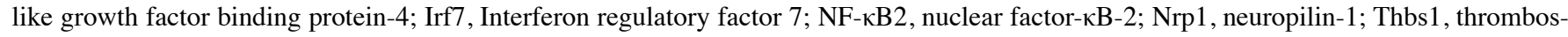
pondin 1; VEGF-A, vascular endothelial growth factor-A; GAPDH, glyceraldehyde 3-phosphate dehydrogenase.

resolving gel and electroblotted onto a polyvinylidene fluoride membrane (Immobilon-P; EMD Millipore). After blocking for $1 \mathrm{~h}$ at room temperature with $3 \%$ bovine serum albumin in Tris-buffered saline with $0.1 \%$ Tween ${ }^{\circledR}-20$, the membrane was incubated overnight at $4{ }^{\circ} \mathrm{C}$ with primary antibodies (diluted at 1:1,000 in 5\% BSA) against B-cell lymphoma (Bcl)-2 (sc-7382, Santa Cruz Biotechnology, Inc.), Bcl-xL (2764, Cell Signaling Technology, Inc.), cyclin-dependent kinase 1 (CDK1) (sc-54, Santa Cruz Biotechnology, Inc.), CDK6 (sc-177, Santa Cruz Biotechnology, Inc.), CDK4 (2906, Cell Signaling Technology, Inc.) and cyclin D1 (2922, Cell Signaling Technology, Inc.), and $\beta$-actin (sc-47778, Santa Cruz Biotechnology, Inc.). The blots were then incubated with peroxidase-conjugated goat anti-mouse and anti-rabbit secondary antibodies (7076 and 7074, respectively, Cell Signaling Technology) diluted at 1:10,000 in 3\% BSA for $1 \mathrm{~h}$ at room temperature. Immunoreactivity was detected by the enhanced chemiluminescent substrate kit (Pierce; Thermo Fisher Scientific, Inc.), and images were captured using a LAS-3000 imaging system (Fujifilm) and the band intensities of blot products were quantified and analyzed using ImageJ software, version $1.52 \mathrm{a}$.

Microarray data analysis. The intensity values of CEL files were normalized to remove bias between the arrays, using the Robust Multi-array Average (RMA) algorithm implemented in the Affymetrix Expression Console software (v1.3.1) (25). Normalized data were imported into the programming software 'R' (v3.0.2) and overall signal distributions of each array were compared using the Bioconductor Project to verify normalization of the data (26). Thereafter, data were $\log 2$-transformed, and differentially expressed genes (DEGs) that exhibited a $>2$-fold difference between the average signal values of the control and treatment groups were selected manually. Additionally, ' $R$ ' was used for the statistical analyses (t-test) on selected DEGs data and genes with $\mathrm{P}<0.05$ were extracted as significant DEGs for further analysis (26). To classify the co-expression of gene groups with similar expression patterns, hierarchical clustering analysis was performed using the Multi Experiment Viewer (v4.4) (27). Finally, using the web-based tool Database for Annotation, Visualization, and Integrated Discovery (DAVID), DEGs were functionally annotated and classified based on the information of gene function, such as OMIM disease, Gene Ontology (GO), Kyoto Encyclopedia of Genes and Genomes (KEGG) pathway, and BioCarta databases to elucidate the regulatory networks in which they are involved (28). Fisher's exact test was performed to assess the relevance of the found pathways and determine the significance of the associations of genes to pathways.

Pathway analysis. Pathway Studio software (v7.1; Ariadne Genomics, Inc.) was used to define the cellular networks and interactions among genes expressed in the microarray experiment. This software contains $>100,000$ regulations, interactions, modifications, and cell process events between proteins and small molecules. An automated text-mining tool, MedScan, enabled the generation of pathways from multiple sources, including the PubMed database and online public sources, such as full text journal and proprietary data sets (literature, experimental, and electronic notebooks) (29). This text information was then converted to biological relationships and imported into the ResNet Mammalian knowledge databases. Thereafter, these associations were used for hypothesis testing, verification and elucidating biological function. Additionally, the gene expression values were visualized and the status in the context of protein interaction networks and pathways were analyzed using Pathway Studio. Gene name were imported into Pathway 
A
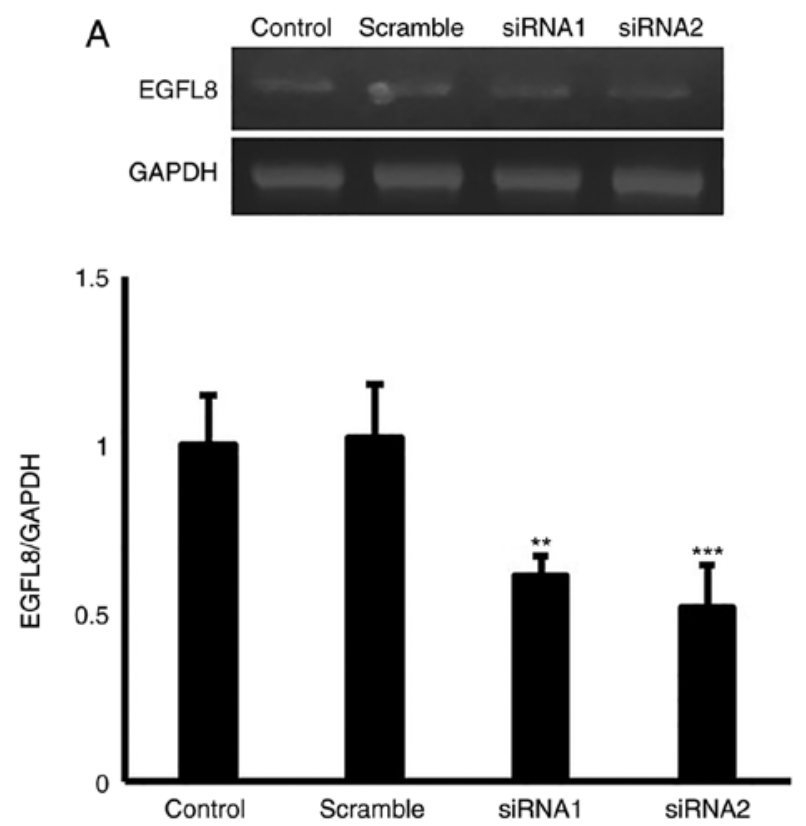

B

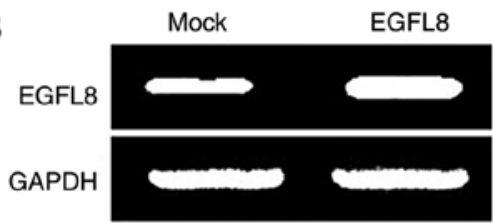

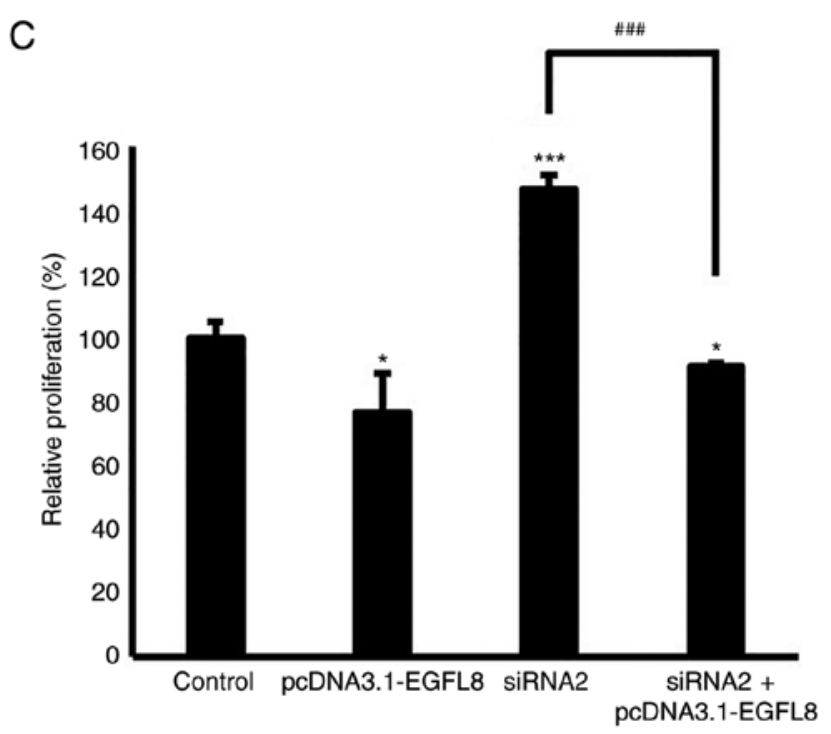

Figure 1. Proliferation of mouse cTECs is modulated via EGFL8 overexpression or knockdown. (A) Validation of the knockdown of mouse EGFL8 gene. EGFL8 mRNA expression to confirm EGFL8 knockdown. Relative expression levels of EGFL8 mRNA were plotted for the EGFL8-silenced cells. (B) Validation of the overexpression of mouse EGFL8 gene. EGFL8 mRNA expression to confirm EGFL8 overexpression. Relative expression levels of EGFL8 mRNA were plotted for the EGFL8-overexpressed cells. (C) Overexpression of EGFL8 in cTECs significantly attenuated cell proliferation, whereas EGFL8 knockdown robustly promoted cell proliferation. Co-transfection with the siRNA and plasmid containing the EGFL8 gene successfully rescued cTECs from EGFL8-siRNA mediated cell proliferation. Data were analyzed using one-way ANOVA. ${ }^{*} \mathrm{P}<0.05,{ }^{* *} \mathrm{P}<0.01,{ }^{* * * *} \mathrm{P}<0.001$ vs. control group; ${ }^{\# \# \#} \mathrm{P}<0.001$ vs. siRNA group. cTECs, cortical thymic epithelial cells; EGFL8, epidermal growth factor-like domain 8.

Studio to identify the cellular processes that were influenced by EGFL8 overexpression or silencing. In the analysis, each identified cellular process was manually curated to identify validated data using the relevant PubMed/Medline hyperlinked abstracts.

Statistical analysis. All data are presented as the means \pm standard deviation (SD) of at least 3 independent experiments. For validation experiments using RT-PCR and western blot analysis, control and sample groups were compared using a one-way analysis of variance (ANOVA) followed by a Tukey's post hoc test. A value of $\mathrm{P}<0.05$ was considered to indicate a statistically significant difference.

\section{Results}

Modulation of cell proliferation induced by EGFL8 in cTECs. To verify efficient EGFL8 transfection and knockdown, cTECs transfected with pcDNA3.1-EGFL8 or EGFL8 siRNA were analyzed by RT-PCR. EGFL8 mRNA expression was analyzed in EGFL8-overexpressing and -silenced cTECs (Fig. 1A and B). To evaluate the regulatory effects of EGFL8 on cell proliferation, cTECs stably transfected with EGFL8 expression vector or EGFL8 siRNA were cultured for 48 h. As shown in Fig. 1C, cell viability was determined in EGFL8-overexpressing and-silenced cTECs and compared with that of the controls. EGFL8 overexpression reduced 
Table II. Hierarchical clustering analysis of differentially expressed genes profile of epidermal growth factor-like domain 8-overexpressing and -silenced cortical thymic epithelial cells.

\begin{tabular}{lccc}
\hline Cell group & Upregulation & Downregulation & Total probes \\
\hline pcDNA3.1 EGFL8 vs. mock & 10 & 33 & 43 \\
EGFL8 siRNA vs. scramble & 192 & 198 & 390 \\
pcDNA3.1 EGFL8 vs. EGFL8 siRNA & 289 & 169 & 458 \\
\hline
\end{tabular}

cell proliferation, whereas EGFL8 knockdown enhanced cell proliferation (Fig. 1C). Furthermore, it was demonstrated that cTECs were successfully 'rescued' from EGFL8 siRNA-mediated cell proliferation when co-transfected with siRNA and plasmid containing the EGFL8 gene, verifying the selectivity and specificity of the knockdown and overexpression of the EGFL8 gene (Fig. 1C).

Identification of DEGs induced by EGFL8 overexpression or silencing. Microarray analysis was used to determine the gene expression profiles of EGFL8-overexpressing and -silenced cTECs. RNAs obtained from the pcDNA3.1-EGFL8-, EGFL8 siRNA-transfected cells, and the mock vector- and scrambled siRNA-transfected cells were amplified, fragmented, labeled and hybridized to Affymetrix GeneChip microarrays containing 28,853 gene-level probe sets. From 28,853 probe sets on the GeneChip ${ }^{\circledR}$ Mouse Gene 1.0 ST arrays, 43 genes $(>2$-fold change, $\mathrm{P}<0.05$ ) were differentially expressed in the cTECs overexpressing EGFL8 compared to the control cells (Table II). A hierarchical clustering analysis revealed that 10 of these genes were upregulated and 33 were downregulated (Fig. 2A and Table II). Additionally, 390 genes (>2-fold change, $\mathrm{P}<0.05)$ were differentially expressed in the EGFL8-silenced cTECs compared to the control cells (Table II). A hierarchical clustering analysis revealed that 192 of these genes were upregulated and 198 were downregulated (Fig. 2B and Table II). Furthermore, 458 genes ( $>2$-fold change, $\mathrm{P}<0.05)$ were differentially expressed in the EGFL8-silenced cTECs compared to the EGFL8-overexpressing cells (Table II). A hierarchical clustering analysis showed that 289 of these genes were upregulated and 169 were downregulated (Fig. 2C and Table II).

GO analysis of DEGs induced by EGFL8 overexpression or silencing. To investigate the biological significance of DEGs induced by EGFL8 overexpression or silencing in cTECs, KEGG pathway analysis was performed. A total of 8 significantly enriched pathways associated with the DEGs were identified. Among the enriched pathways in the upregulated and downregulated DEGs, cytokine-cytokine interaction, focal adhesion, axon guidance, p53 signaling, endocytosis, pathways in cancer, steroid biosynthesis and terpenoid backbone biosynthesis of TECs were annotated $(\mathrm{P}<0.05$; Table III).

Furthermore, genes were categorized based on the GO analysis, illustrated in Fig. 3. The functions of DEGs were characterized using GO terms. GO was was utilized to investigate the nature of the EGFL8-associated genes identified by microarray data analyses. Fisher's exact test with $\mathrm{P}<0.05$ and gene frequency (gene count assigned to an annotation term) of $>2 \%$ was set as the threshold to select over-represented
GO biological processes. Enrichment in the processes of cell proliferation, differentiation, adhesion, cycle and migration, as well as in the regulation of immune responses and transcription was noted.

Validation of DEGs induced by EGFL8 knockdown. To confirm the results of microarray analysis, the expression patterns of genes associated with cell proliferation were evaluated in EGFL8 siRNA-transfected cTECs. The FasL, CXCL10 and CXCL16 genes were selected on the basis of their potential role in cell proliferation and adhesion. As shown in Fig. 4, EGFL8 knockdown upregulated the expression levels of FasL, CXCL5, CXCL10, CXCL16 and CCL20, whereas it downregulated those of Nrp1 in cTECs.

In the present study, the potential role of EGFL8 in angiogenesis was evaluated. As shown in Fig. 5, EGFL8 knockdown reduced the expression levels of Angptl, whereas it augmented those of VEGF-A, CD74 and NF- $\mathrm{kB} 2$ in the cTECs. Furthermore, it was found that EGFL8 knockdown promoted the gene expression of IGFBP-4, Thbs1 and Irf7 in cTECs (Fig. 6).

To determine the effects of EGFL8 on the expression of apoptosis- and cell cycle-related proteins, EGFL8 siRNAs were stably transfected into cTECs. Differential protein expression levels of Bcl-2, Bcl-xL, CDK1, CDK4, CDK6 and cyclin D1 were observed for the EGFL8-silenced cTECs. As shown in Fig. 7, EGFL8 knockdown increased the expression of apoptosis-related molecules, Bcl-2 and Bcl-xL in the cTECs. Additionally, EGFL8 knockdown enhanced the expression of the key cell cycle regulatory molecules, CDK1, CDK4, CDK6 and cyclin D1 proteins in the cTECs (Fig. 8).

Interaction network analysis of DEGs induced by EGFL8 overexpression or silencing in cTECs. To further investigate the key pathways utilized by the identified DEGs, the analysis of multi-genic pathways depicting possible molecular interactions that define biologic activities based on related sets of DEGs was performed and visualized using Pathway Studio software. In-depth literature mining with Pathway Studio revealed that a high percentage of the EGFL8-associated genes are involved in cell proliferation (20\%), apoptosis (19\%), differentiation (15\%), growth (12\%), migration (10\%), immune response $(7 \%)$, cell cycle $(7 \%)$, reactive oxygen species (ROS) generation (7\%) and chemotaxis (3\%) (Fig. 9). These are biological processes that regulate crucial cellular functions, and whose deregulation is commonly observed in diseases. Biological networks of all known associations and potential interactions between the DEGs are shown in Fig. 10. A possible gene network using the 344 genes mapped by the 
Table III. Kyoto Encyclopedia of Genes and Genomes enrichment analysis of biological pathways.

\begin{tabular}{|c|c|c|c|c|c|}
\hline KEGG analysis & Expression & $\begin{array}{l}\text { Enriched } \\
\text { gene }\end{array}$ & Gene description & $\begin{array}{c}\text { Fold } \\
\text { change }\end{array}$ & P-value \\
\hline \multirow{13}{*}{$\begin{array}{l}\text { Cytokine-cytokine } \\
\text { receptor interaction }\end{array}$} & \multirow[t]{7}{*}{ Upregulated } & Cxcl10 & Chemokine (C-X-C motif) ligand 10 & 3.753 & \multirow[t]{13}{*}{0.009} \\
\hline & & Cxcl16 & Chemokine (C-X-C motif) ligand 16 & 2.86 & \\
\hline & & Cxcl5 & Chemokine (C-X-C motif) ligand 5 & 2.813 & \\
\hline & & Vegfa & Vascular endothelial growth factor-A & 2.741 & \\
\hline & & Osmr & Oncostatin $\mathrm{M}$ receptor & 2.643 & \\
\hline & & Fas & Fas (TNF receptor super family member 6 ) & 2.506 & \\
\hline & & Inhbe & Inhibin beta $\mathrm{E}$ & 2.2 & \\
\hline & \multirow[t]{6}{*}{ Downregulated } & Pdgfc & Platelet-derived growth factor, C polypeptide & 2.082 & \\
\hline & & Inhba & Inhibin beta-A & 2.535 & \\
\hline & & Figf & c-fos induced growth factor & 2.644 & \\
\hline & & Met & MET proto-oncogene & 2.676 & \\
\hline & & $\mathrm{Cxcl} 12$ & Chemokine (C-X-C motif) ligand 12 & 2.705 & \\
\hline & & Il18rap & Interleukin 18 receptor accessory protein & 2.822 & \\
\hline \multirow[t]{12}{*}{ Focal adhesion } & \multirow[t]{3}{*}{ Upregulated } & Vegfa & Vascular endothelial growth factor-A & 2.741 & \multirow[t]{12}{*}{0.005} \\
\hline & & Fyn & Fyn proto-oncogene & 2.066 & \\
\hline & & Ccnd2 & Cyclin D2 & 2.012 & \\
\hline & \multirow[t]{9}{*}{ Downregulated } & Ccnd1 & Cyclin D1 & 3.138 & \\
\hline & & Pdgfc & Platelet-derived growth factor, $\mathrm{C}$ polypeptide & 2.607 & \\
\hline & & Col3a1 & Collagen, Type III, alpha 1 & 2.353 & \\
\hline & & Thbs 1 & Thrombospondin 1 & 2.042 & \\
\hline & & Igf1r & Insulin-like growth factor 1 receptor & 2.082 & \\
\hline & & Cav2 & Caveolin 2 & 2.368 & \\
\hline & & Cav1 & Caveolin 1 , caveolae protein & 2.676 & \\
\hline & & Figf & c-fos induced growth factor & 2.644 & \\
\hline & & Met & MET proto-oncogene & 2.676 & \\
\hline \multirow[t]{10}{*}{ Axon guidance } & \multirow[t]{2}{*}{ Upregulated } & Rnd1 & Rho family GTPase 1 & 2.477 & \multirow[t]{10}{*}{0.003} \\
\hline & & Fyn & Fynproto-oncogene & 2.066 & \\
\hline & \multirow[t]{8}{*}{ Downregulated } & Sema7a & Sema domain, Semaphorin 7A & 2.040 & \\
\hline & & Sema3c & Sema domain, Semaphorin 3C & 2.098 & \\
\hline & & Sema3e & Sema domain, Semaphorin 3E & 2.139 & \\
\hline & & Met & MET proto-oncogene & 2.676 & \\
\hline & & $\mathrm{Cxcl} 12$ & Chemokine (C-X-C motif) ligand 12 & 2.705 & \\
\hline & & Epha4 & EPH receptor A4 & 2.861 & \\
\hline & & Nrp1 & Neuropilin 1 & 3.669 & \\
\hline & & Sema3d & Sema domain, Semaphorin 3D & 4.986 & \\
\hline \multirow[t]{6}{*}{ p53 signaling pathway } & \multirow[t]{4}{*}{ Upregulated } & Gadd45a & Growth arrest and DNA-damage-inducible 45 alpha & 4.074 & \multirow[t]{6}{*}{0.02} \\
\hline & & Fas & Fas (TNF receptor super family member 6) & 2.506 & \\
\hline & & $\operatorname{Sesn} 2$ & Sestrin 2 & 2.338 & \\
\hline & & Ccnd2 & Cyclin D2 & 2.012 & \\
\hline & \multirow[t]{2}{*}{ Downregulated } & Ccnd 1 & Cyclin D1 & 2.042 & \\
\hline & & Thbs 1 & Thrombospondin 1 & 2.334 & \\
\hline \multirow[t]{9}{*}{ Endocytosis } & \multirow[t]{3}{*}{ Upregulated } & Pip5k1b & Phosphatidylinositol-4-phosphate 5-kinase, type 1 beta & 2.208 & \multirow[t]{9}{*}{0.039} \\
\hline & & $\mathrm{H} 2-\mathrm{K} 1$ & Histocompatibility $2, \mathrm{~K} 1, \mathrm{~K}$ region & 2.1 & \\
\hline & & H2-Q6 & Histocompatibility 2, Q region locus 6 & 2.05 & \\
\hline & \multirow[t]{6}{*}{ Downregulated } & Igfl1r & Insulin like growth factor 1 receptor & 2.368 & \\
\hline & & Adrb2 & Adrenergic receptor, beta 2 & 2.481 & \\
\hline & & Hspa1a & Heat shock protein $1 \mathrm{~A}$ & 2.572 & \\
\hline & & Ehd2 & EH domain containing 2 & 2.607 & \\
\hline & & Met & MET proto-oncogene & 2.676 & \\
\hline & & Tfrc & Transferrin receptor & 2.736 & \\
\hline
\end{tabular}


Table III. Continued.

\begin{tabular}{|c|c|c|c|c|c|}
\hline KEGG analysis & Expression & $\begin{array}{l}\text { Enriched } \\
\text { gene }\end{array}$ & Gene description & $\begin{array}{l}\text { Fold } \\
\text { change }\end{array}$ & P-value \\
\hline & & Ldlr & Low density liproprotein receptor & 4.541 & \\
\hline \multirow[t]{17}{*}{ Pathways in cancer } & Upregulated & Fgf21 & Fibroblast growth factor 21 & 3.138 & 0.002 \\
\hline & & Nos2 & Nitric oxide synthase 2 , inducible & 3.097 & \\
\hline & & Vegfa & Vascular endothelial growth factor-A & 2.741 & \\
\hline & & $\mathrm{Rb} 1$ & Retinoblastoma 1 & 2.607 & \\
\hline & & Fas & Fas (TNF receptor superfamily member 6) & 2.506 & \\
\hline & & Nfkb2 & $\begin{array}{l}\text { Nuclear factor of kappa light polypeptide } \\
\text { gene enhancer in B-cells 2, p49/p100 }\end{array}$ & 2.478 & \\
\hline & & Fzd4 & Frizzled homolog 4 (Drosophila) & 2.368 & \\
\hline & & Mitf & $\begin{array}{l}\text { Microphthalmia-associated transcription } \\
\text { factor }\end{array}$ & 2.353 & \\
\hline & & Brca2 & Breast cancer 2 & 2.238 & \\
\hline & & Statl & $\begin{array}{l}\text { Signal transducer and activator of } \\
\text { transcription } 1\end{array}$ & 2.171 & \\
\hline & Downregulated & Ccdn 1 & Cyclin D1 & 2.042 & \\
\hline & & Jup & Junction plakoglobin & 2.14 & \\
\hline & & Igf1r & Insulin like growth factor 1 receptor & 2.368 & \\
\hline & & Bmp4 & Bone morphogenetic protein 4 & 2.637 & \\
\hline & & Figf & c-fos-induced growth factor & 2.644 & \\
\hline & & Met & MET proto-oncogene & 2.676 & \\
\hline & & Fos & Fos proto-oncogene & 3.391 & \\
\hline \multirow{8}{*}{$\begin{array}{l}\text { Steroid } \\
\text { biosynthesis }\end{array}$} & Upregulated & Soat 2 & Sterol O-acyltransferase 2 & 3.395 & 0.000 \\
\hline & Downregulated & Sqle & Squalene epoxidase & 2.040 & \\
\hline & & Fdft1 & Farnesyl-diphosphate farnesyltransferase 1 & 2.182 & \\
\hline & & Hsd17b7 & Hydroxysteroid 17-beta dehydrogenase 7 & 2.468 & \\
\hline & & Dhcr7 & 7-dehydrocholesterol reductase & 2.520 & \\
\hline & & Nsdhl & NAD(P) dependent steroid dehydrogenase-like & 2.917 & \\
\hline & & Cyp51 & Cytochrome P450, family 51 & 3.040 & \\
\hline & & Dhcr24 & 24-Dehydrocholesterol reductase & 3.383 & \\
\hline \multirow{6}{*}{$\begin{array}{l}\text { Terpenoid } \\
\text { backbone } \\
\text { biosynthesis }\end{array}$} & Upregulated & - & - & - & 0.000 \\
\hline & Downregulated & Hmgcr & 3-Hydroxy-3-methylglutaryl-CoA reductase & 2.002 & \\
\hline & & Acat2 & Acetl-CoA acetyltransferase 2 & 2.257 & \\
\hline & & Mvd & Mevalonate (diphospho) decarboxylase & 2.732 & \\
\hline & & Idi1 & Isopentenyl-diphosphate delta isomerase 1 & 3.507 & \\
\hline & & Hmges1 & 3-Hydroxy-3-methylglutaryl-CoA synthase 1 & 3.797 & \\
\hline
\end{tabular}

algorithms 'expression' and 'regulation' to filter the associations from 458 total genes that were differentially expressed between the EGFL8-overexpressing and -silenced cTECs was identified. The associations of the mapped DEGs were linked to each other based on previously published literature. DEGs that share associations were displayed in the network and unlinked genes were excluded from it (Fig. 10). Pathway analysis depicted the expression pattern of upregulated and downregulated genes in EGFL8-overexpressing or -silenced cTECs. In the extracellular region, the expression of CCL20, IGFBP4, lipocalin 2 (LCN2) and carbonic anhydrase VI (CA6) was upregulated, whereas that of Sema3D, Angpt1 and prolactin family 2 subfamily c member $3(\operatorname{Prl} 2 \mathrm{c} 3)$ was downregulated (Fig. 10). In the plasma membrane, the expression of CD74 and solute carrier family 7 member 11 (SLC7A11) was upregulated, whereas that of aquaporin 1 (AQP1) was downregulated (Fig. 10). In the cytoplasmic region, the expression of cytochrome b5 reductase 2 (CYB5R2) and ubiquitin specific peptidase 18 (USP18) was upregulated, whereas that of SH2 domain-containing protein 1B (SH2D1B) was downregulated (Fig. 10). In the nuclear region, the expression of activating transcription factor 3 (ATF3) was upregulated (Fig. 10). KEGG, GO and Pathway Studio analyses of DEGs associated with EGFL8 modulation in cTECs revealed 2 overlaps of enriched pathways involved in the cell cycle regulation and immune responses (Fig. 11).

In a second analysis, 'network connectivity' was examined to identify genes that are highly linked to the proteins 
Table IV. Epidermal growth factor-like domain 8-associated gene network connectivity. Top 11 nodes with more than 4000 connectivity.

\begin{tabular}{llr}
\hline Gene name & Gene symbol & Connectivity \\
\hline Vascular endothelial growth factor-A & VEGF-A & 15,004 \\
Cyclin D1 & CCND1 & 6,846 \\
FBJ murine osteosarcoma viral oncogene homolog & FOS & 6,527 \\
Heat shock protein family A (Hsp70) member 1A & HSPA1A & 6,480 \\
Nerve growth factor & NGF & 5,940 \\
Vascular cell adhesion molecule 1 & VCAM1 & 4,869 \\
C-X-C motif chemokine ligand 12 & CXCL12 \\
Caveolin 1 & CAV1 & 4,860 \\
Signal transducer and activator of transcription 1 & STAT1 & 4,702 \\
Insulin like growth factor 1 receptor & IGF1R & 4,401 \\
C-X-C motif chemokine ligand 10 & CXCL10 & 4,140 \\
\end{tabular}

regulated by EGFL8 (i.e., to identify a common node). As a result, 49 genes were found to be nodes having a connectivity $>1,000$. The nodes having connectivity a $>4,000$ are listed in Table IV. Notably, VEGF-A, was determined to be the node with the highest degree of connectivity $(15,004)$ between the EGFL8-associated genes (Fig. 12).

\section{Discussion}

cTECs play a central role in physiological $\mathrm{T}$ cell development and thymopoiesis during regeneration from thymic involution, which leads to $\mathrm{T}$ cell depletion $(4,30)$. In the present study, microarray analysis was applied to identify candidate genes responsible for EGFL8-regulated cellular functions in TECs using the gain- and loss-of function mutations of EGFL8. The findings of this study corroborate the hypothesis that EGFL8 can serve as a key molecule regulating several fundamental functions of cTECs, such as cell proliferation and signaling.

The results presented in the present study identified genes that are differentially expressed based on statistical evaluations of the manipulation of EGFL8 expression levels in cTECs. Notably, the present study provided direct evidence for the involvement of EGFL8 in the inhibition of TEC proliferation. The mechanisms underlying the suppressed cell proliferation induced by EGFL8 may be attributed to the inhibition of cell cycle progression and induction of apoptosis as EGFL8 knockdown elevated expression levels of important cell cycle regulatory molecules, such as CDK1, CDK4, CDK6 and cyclin D1. Additionally, the expression of the anti-apoptotic genes, Bcl-2 and Bcl-xL, was increased. Furthermore, the present study demonstrated that EGFL8 significantly modulated the expression of genes related to the following: i) Regulatory factors of $\mathrm{T}$ cell development, such as, FasL, Nrp1, IGFBP-4 and Thbs1; ii) T cell chemotactic migration, such as CCL20, CXCL5, CXCL10 and CXCL16; iii) Important transcription factors, such as Irf7 and $\mathrm{NF}-\kappa \mathrm{B} 2$; and iv) Angiogenic factors, such as Angptl1, ANGPT1, CD74 and VEGF-A.

TECs express a variety of proteins that regulate $\mathrm{T}$ cell survival, proliferation and maturation in the thymus. Among these, FasL (CD95L/APO-1L), a TNF family member, plays a functional role in the proliferation of activated $\mathrm{T}$ cells. The cross-linking of FasL in $\mathrm{CD}^{+} \mathrm{T}$ cells is required for maximal cellular proliferation in vivo (31). In the present study, the silencing of EGFL8 gene expression with EGFL8-specific siRNA upregulated the expression level of FasL in cTECs. A previous study demonstrawted that EGFL8 significantly inhibited the expression of IL-7 in TECs (22). FasL plays a direct regulatory role through IL-7 activation, which increases its efficacy to induce proliferation of sub-optimally activated T cells (32). Thus, it was hypothesized that the EGFL8-induced changes in FasL expression levels in cTECs may be implicated in the regulation of proliferation of $\mathrm{T}$ cell precursors.

Nrp1 is a non-tyrosine kinase trans-membrane glycoprotein and is a high-affinity receptors for semaphorins on the cell membrane (33). Semaphorin signaling plays an important role in focal adhesion assembly/disassembly and induces cytoskeletal remodeling, thereby affecting cell shape, attachment to the extracellular matrix, cell motility, and cell migration $(34,35)$. Sema3D and Nrp1 are expressed in the thymus, and Sema7A is expressed by thymocytes, predominantly in immature $\mathrm{CD}^{+}{ }^{+} \mathrm{CD} 8^{+}$and mature $\mathrm{CD} 4{ }^{-} \mathrm{CD} 8^{-}$subsets $(36,37)$. It has been reported that the expression of Nrp1 increases with age and Nrp1 may play a significant role in the regulation of thymic involution $(35,37)$. However, the exact role of Nrp1 in the thymus function requires further investigation.

Chemokines, the largest family of cytokines in human immunophysiology, are involved in recruiting lymphocytes, neutrophils, and macrophages during an immune response, thereby functioning as signaling proteins of the immune system (38). CXCL10 (IP-10), a small pro-inflammatory chemotactic polypeptide, is associated with recruiting $\mathrm{T}$ cell precursors to the thymus (39). CXCL16 promotes lymphocyte adhesion to epithelial cells through integrin-mediated signaling (40). The chemokine ligand CCL20 is expressed in various types of epithelial cells, including TECs (41). CC chemokine receptor 6 (CCR6), the specific chemokine receptor of CCL20, is expressed by $\mathrm{T}$ cells, and the CCL20/CCR6 axis is involved in the 


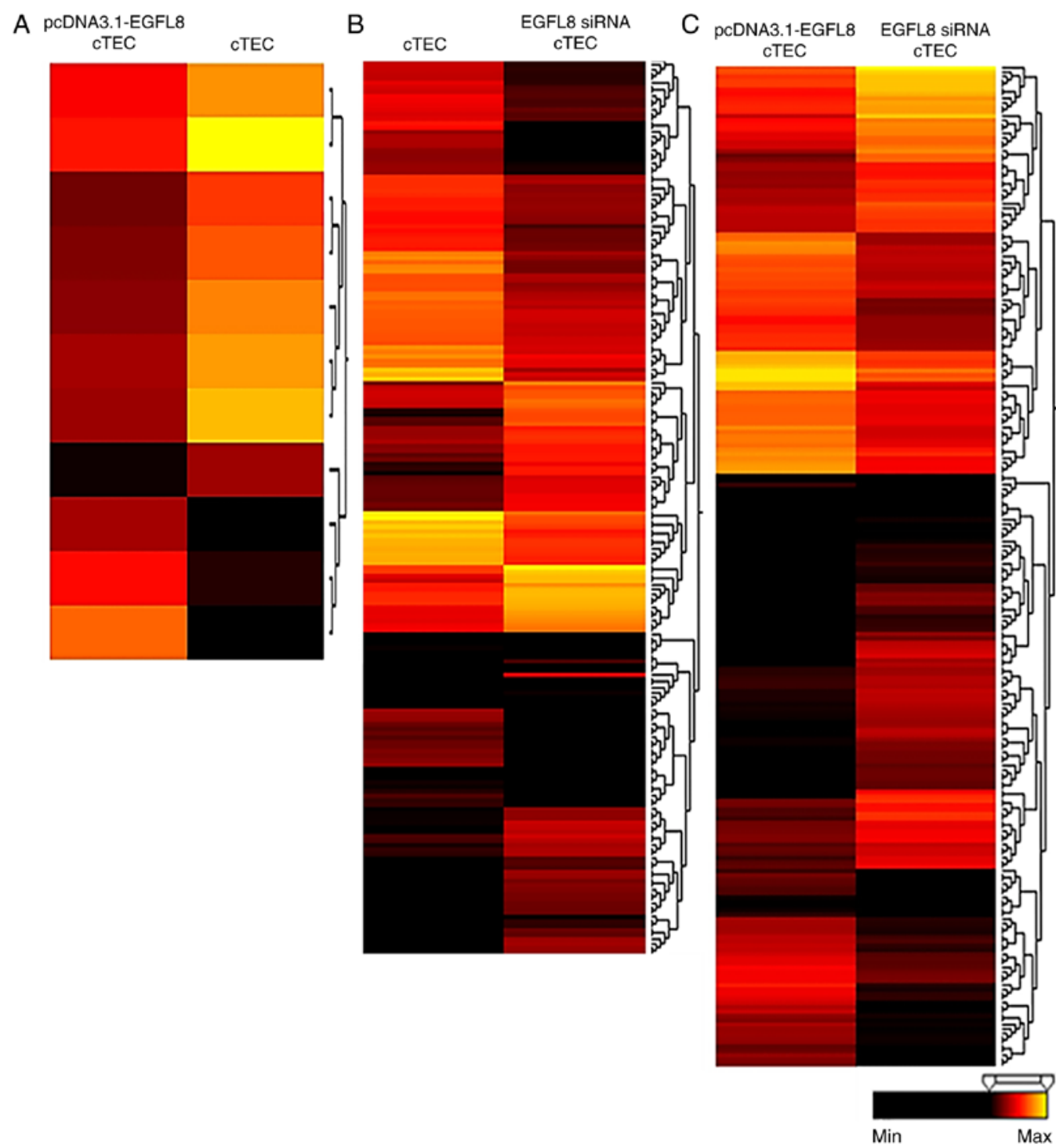

Figure 2. Identification of differentially expressed genes (DEGs) depicted by a heatmap. (A) DEGs in the pcDNA3.1-EGFL8-transfected vs. the mock-transfected cTECs. (B) DEGs in the EGFL8 siRNA-transfected vs. the scrambled siRNA-transfected cTECs. (C) DEGs in the EGFL8 siRNA-transfected vs. the pcDNA3.1-EGFL8-transfected cTECs. cTECs, cortical thymic epithelial cells; EGFL8, epidermal growth factor-like domain 8.

migration of $\mathrm{CCR}^{+} \mathrm{T}$ cells (42). Additionally, there is evidence to suggest that CXCL5 is linked to immune cell recruitment (43). A previous study using CXCL5-deficient mice demonstrated that the expression levels of $N F-\kappa B$, mitogen-activated protein kinase (MAPK) and intercellular adhesion molecule-1 (ICAM-1) were reduced in the lungs during exposure to secondhand smoke (43). In the present study, it was demonstrated that EGFL8 knockdown upregulated the expression of CXCL5. In a previous study, it was demonstrated that EGFL8 significantly inhibited the adhesion of thymocytes to TECs through the attenuation of ICAM-1 expression therein (22). Hence, it is possible that EGFL8 inhibits the adhesion of thymocytes to TECs by downregulating the expression of chemokines, including CXCL5, which in turn leads to diminished production of ICAM-1 in TECs. Overall, the current results indicate that EGFL8 knockdown augments the expression of CXCL5, CXCL10, CXCL16 and CCL20. This suggests the important role of EGFL8 in cTECs for the recruitment of $\mathrm{T}$ cell precursors to the thymus and for TEC-thymocyte interactions via attenuation of chemokine production.

The results of the present study demonstrating that the expression of Angptl1 was decreased in EGFL8-silenced TECs, and vice versa for VEGF-A, CD74, and NF- $\mathrm{B} 2$ suggest that EGFL8 affects angiogenesis by modulating the expression of Angptl1, VEGF-A, CD74 and NF-кB2. Angptl1 (also known as angioarrestin), a key anti-angiogenic protein, is essential for the regulation of VEGF-A, which is a key signaling protein that stimulates vasculogenesis and angiogenesis (44). CD74 is an integral membrane protein that functions as an MHC class II chaperone, and an accessory-signaling molecule with a distinct role in angiogenesis and inflammation by binding to the pro-inflammatory cytokine, macrophage migration-inhibitory factor $(45,46)$. $\mathrm{NF}-\kappa \mathrm{B}$ is a pleiotropic transcription factor present in the majority of cell types and is the endpoint of a series of signal transduction events that are initiated by numerous stimuli related to inflammation, immunity, cell differentiation, growth, adhesion, apoptosis and 


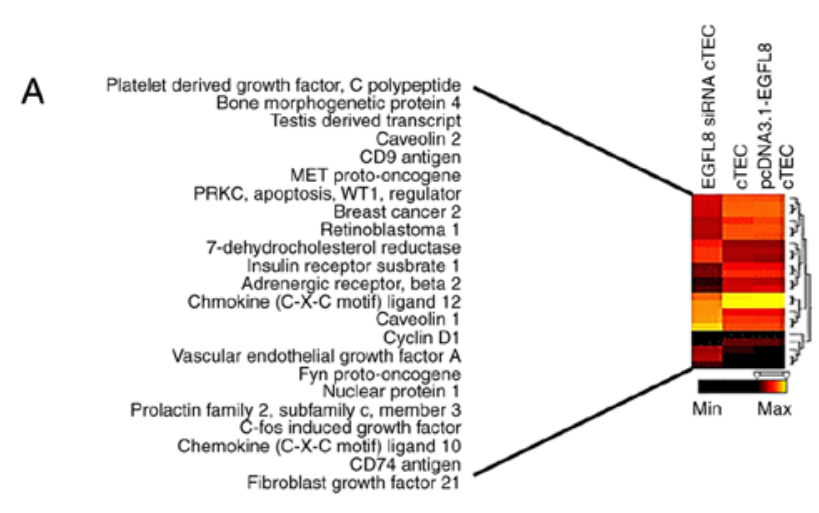

B
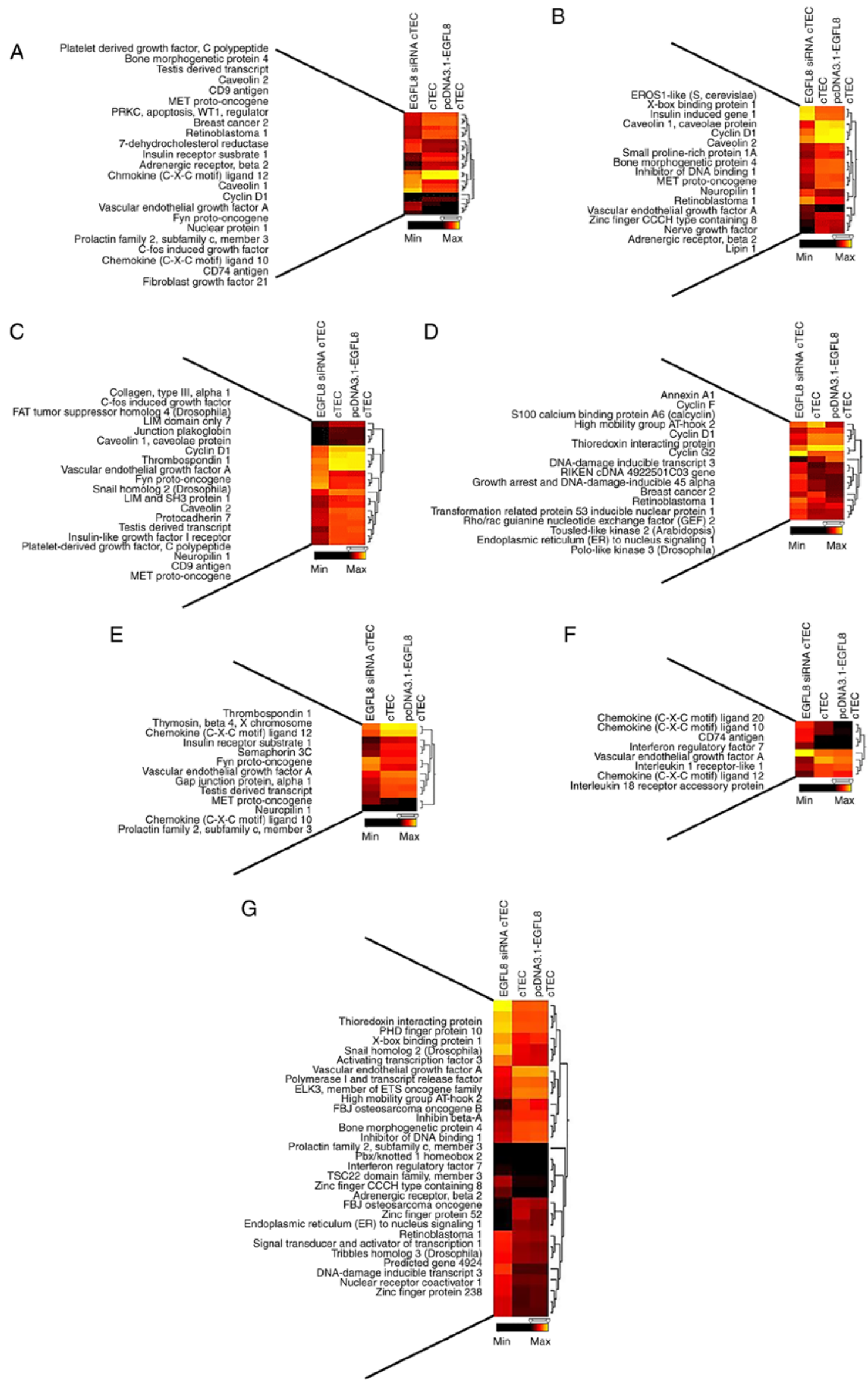

Figure 3. Functional categorization of genes up- or downregulated in EGFL8-overexpressing or -silenced cTECs. (A) Cell proliferation, (B) cell differentiation, (C) cell adhesion, (D) cell cycle, (E) cell migration, (F) immune response, and (G) regulation of transcription. cTECs, cortical thymic epithelial cells; EGFL8, epidermal growth factor-like domain 8. 
A
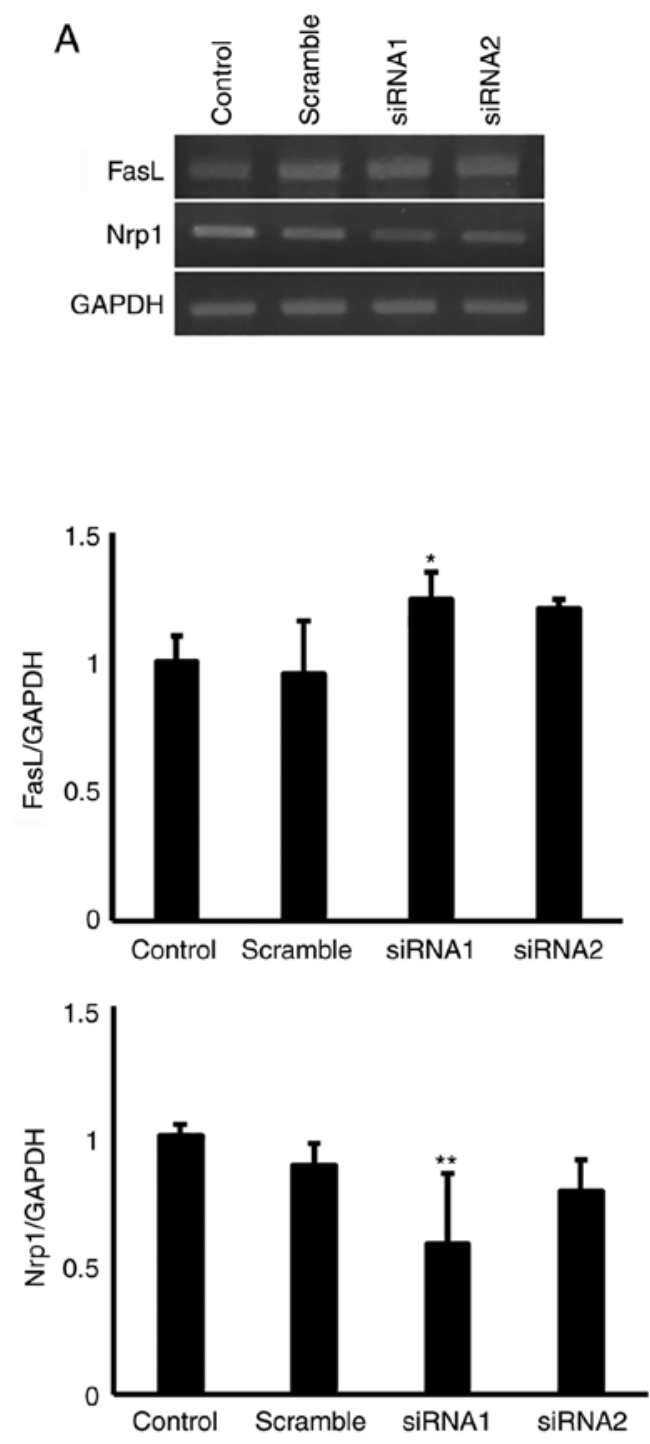

B
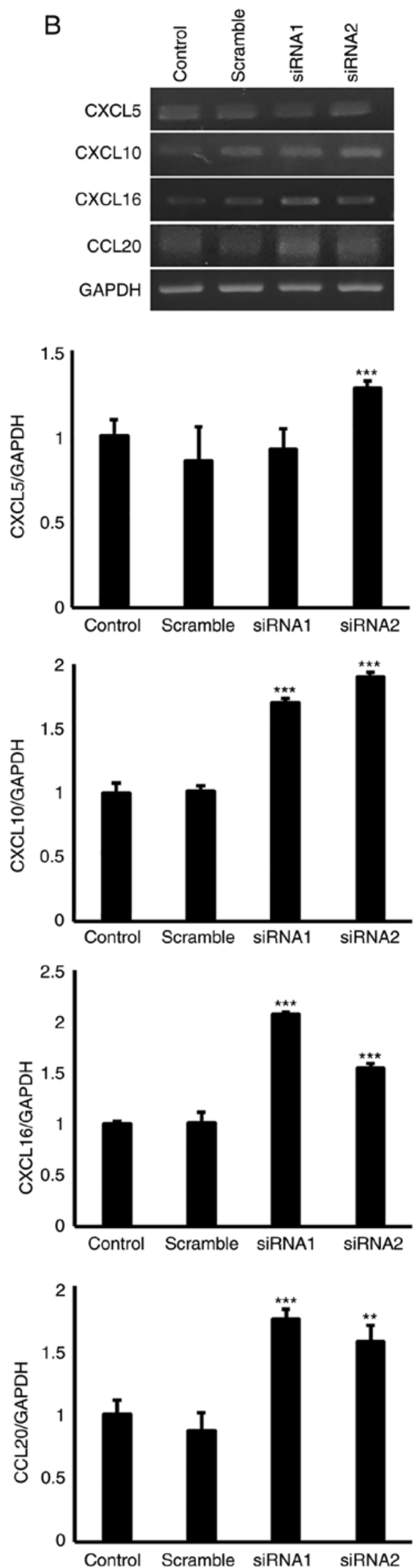

Figure 4. Mouse cTECs were transfected with EGFL8 siRNA; EGFL8 knockdown increased the expression of (A) FasL and Nrp1 and (B) CXCL5, CXCL10, CXCL16 and CCL20. Data were analyzed using one-way ANOVA. ${ }^{*} \mathrm{P}<0.05,{ }^{* *} \mathrm{P}<0.01,{ }^{* * *} \mathrm{P}<0.001$. cTECs, cortical thymic epithelial cells; EGFL8, epidermal growth factor-like domain 8; FasL, Fas ligand; Nrp1, neuropilin-1; CXCL, C-X-C motif chemokine ligand; CCL20, chemokine ligand 20. 
A
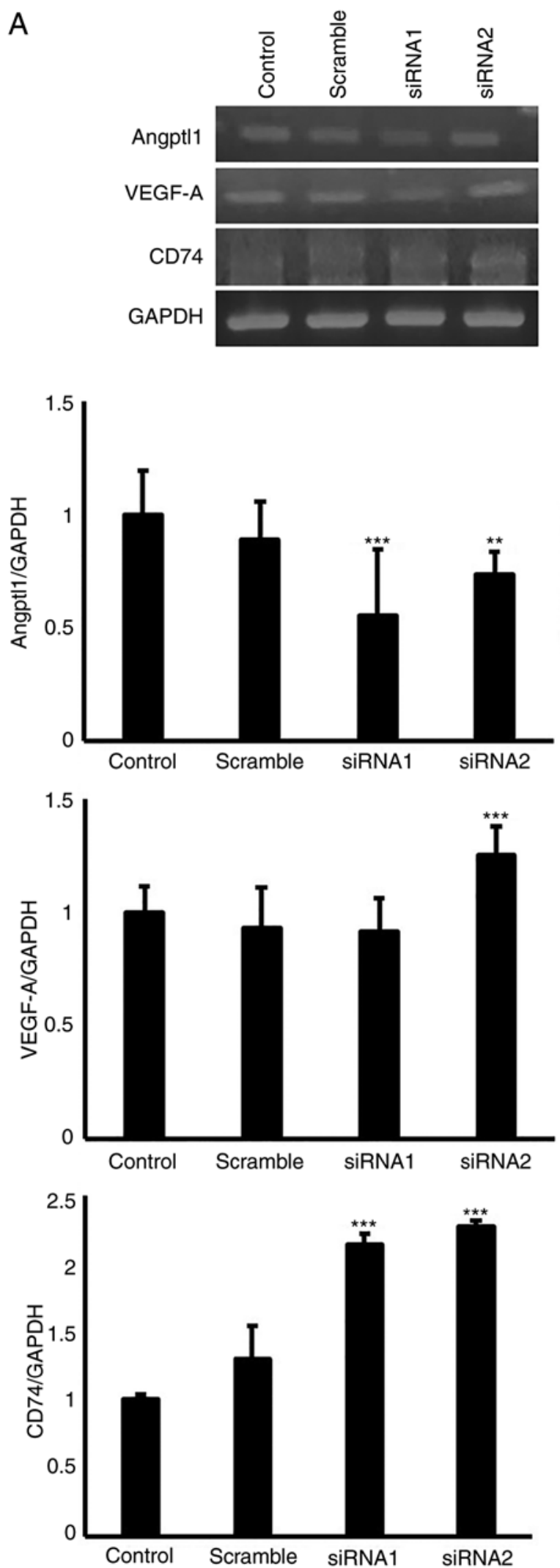

B
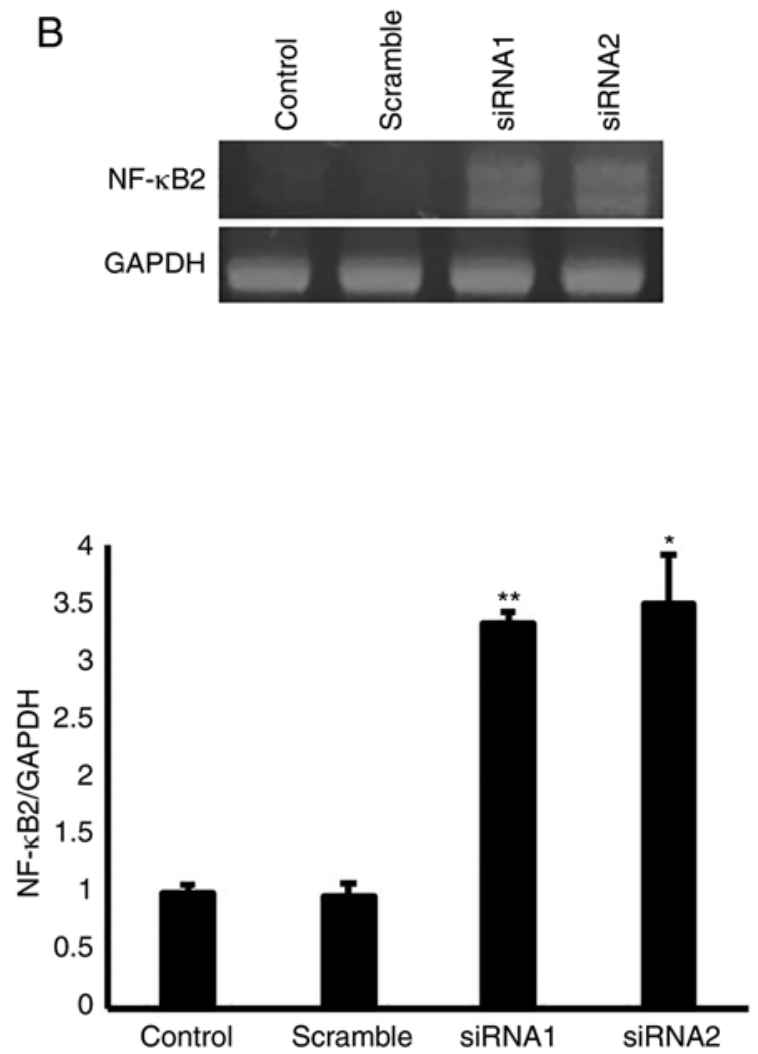

Figure 5. Mouse cTECs were transfected with EGFL8 siRNA; EGFL8 knockdown (A) suppressed the gene expression of Angptl1 but augmented that of VEGF-A, CD74, and (B) nuclear factor $\kappa \mathrm{B}$ subunit 2 (NF- $\kappa \mathrm{B} 2)$. Data were analyzed using one-way ANOVA. ${ }^{*} \mathrm{P}<0.05,{ }^{* *} \mathrm{P}<0.01,{ }^{* * *} \mathrm{P}<0.001$. cTECs, cortical thymic epithelial cells; EGFL8, epidermal growth factor-like domain 8; Angptl1, angiopoietin-like 1; VEGF-A, vascular endothelial growth factor-A; CD74, cluster differentiation 74; NF- $\kappa$ B2, nuclear factor $\kappa \mathrm{B}$ subunit 2.

tumorigenesis. It has been shown that $\mathrm{NF}-\kappa \mathrm{B} 2$ is involved in the upregulation of VEGF mRNA (47).
IGFBP-4 binds and titrates IGF-2 away from the IGF receptor, thereby inhibiting IGF-2 signaling, which 

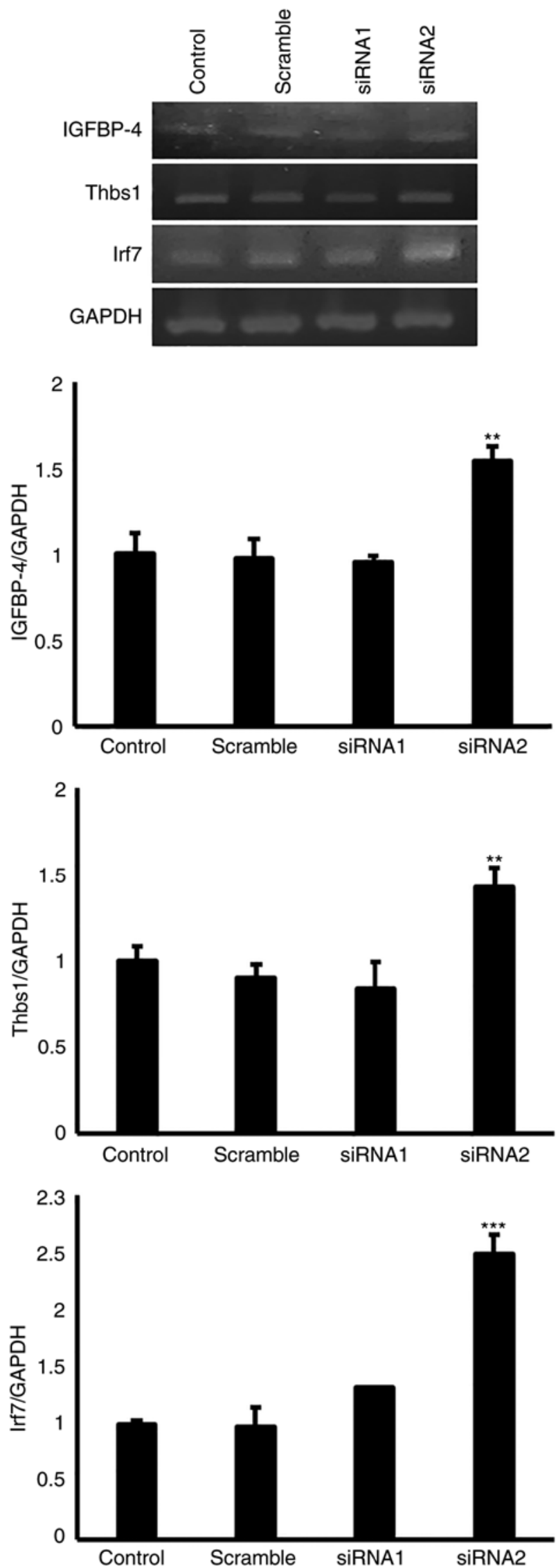

Figure 6. Mouse cTECs were transfected with EGFL8 siRNA and EGFL8 knockdown upregulated the expression levels of IGFBP-4, Thbs1 and Irf7. Data were analyzed using one-way ANOVA. ${ }^{* *} \mathrm{P}<0.01,{ }^{* * *} \mathrm{P}<0.001$. cTECs, cortical thymic epithelial cells; EGFL8, epidermal growth factor-like domain 8; IGFBP-4, insulin-like growth factor binding protein-4; Thbs1, thrombospondin 1; Irf7, interferon regulatory factor 7.
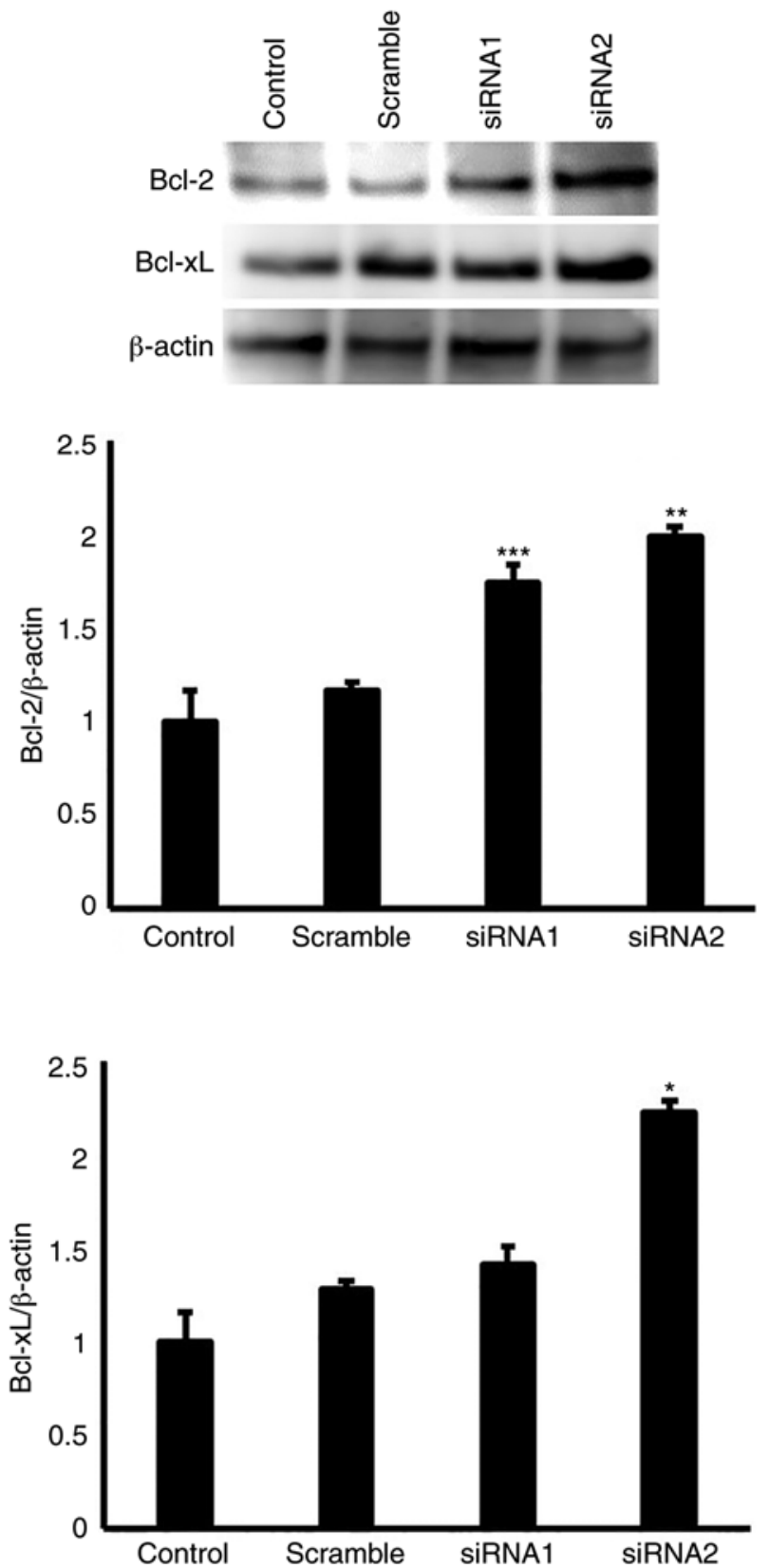

Figure 7. Mouse cTECs were transfected with EGFL8 siRNA showing that EGFL8 knockdown increased the expression levels of apoptosis-related molecules Bcl-2 and Bcl-xL. Data were analyzed using one-way ANOVA. ${ }^{*} \mathrm{P}<0.05,{ }^{* *} \mathrm{P}<0.01,{ }^{* * *} \mathrm{P}<0.001$. cTECs, cortical thymic epithelial cells; EGFL8, epidermal growth factor-like domain 8.

reduces apoptosis via the activation of the phosphoinositide 3-kinase/protein kinase B (PI3K/Akt) and MAPK pathways (48). Thbs1 has been suggested to participate in TEC-thymocyte interaction, which is involved in the differentiation of thymocytes into mature T cells (49). Irf7 is essential for the development of TECs and maintenance of thymic architecture through interferon $\alpha / \beta$ receptor subunit 1 (IFNAR1) and signal transducer and activator of transcription 1 (STAT1) signaling (50). The results of the present study suggest that EGFL8 may be involved in several fundamental processes of cTECs, including survival, proliferation, and adhesion by regulating the expression of IGFBP-4, Irf7 and Thbs1. 

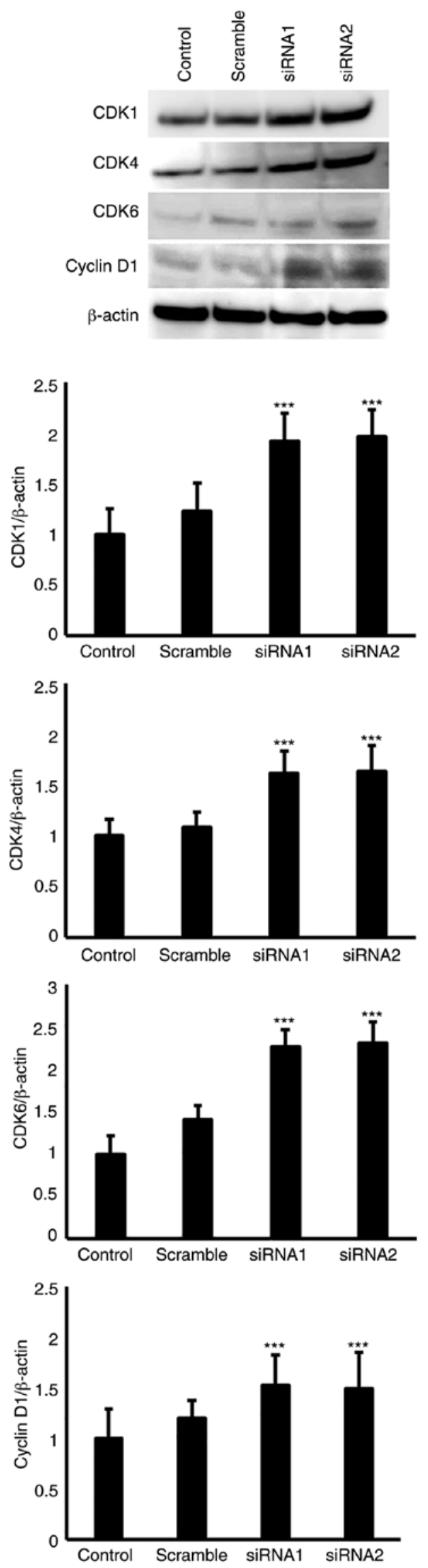

Figure 8. Mouse cTECs were transfected with EGFL8 siRNA; EGFL8 knockdown increased the expression of cell cycle regulatory proteins, CDK1, CDK4, CDK6, and cyclin D1. Data were analyzed using one-way ANOVA. ${ }^{* * * *} \mathrm{P}<0.001$. cTECs, cortical thymic epithelial cells; EGFL8, epidermal growth factor-like domain 8 ; $\mathrm{CDK}$, cyclin-dependent kinase.

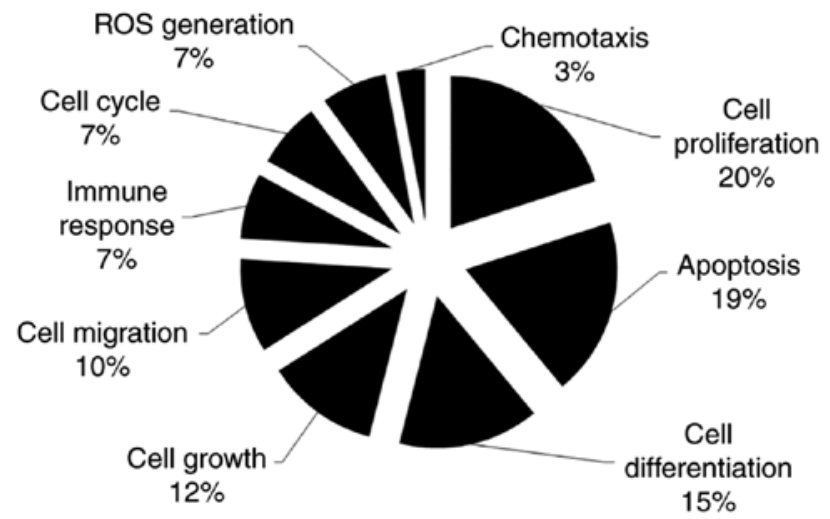

Figure 9. Classification of biological processes of EGFL8-associated genes. EGFL8, epidermal growth factor-like domain 8.

The interaction network analysis performed using Pathway Studio software also mapped signaling pathways associated with cell cycle, proliferation, growth, differentiation, and migration, as well as apoptosis, ROS generation, chemotaxis and immune response, supporting the results of KEGG and $\mathrm{GO}$ analyses. Overall, the results of the present study demonstrated that DEGs induced by elevated or silenced EGFL8 expression in cTECs play a role in cell proliferation, apoptosis, differentiation, growth, migration and immune response, which are critical to the physiology of cTECs. Moreover, pathway analysis revealed the putative network of DEGs and their localization within the cell. This analysis demonstrated that DEGs of cell surface receptors in the plasma membrane, signal transduction molecules in the cytosol, transcription factors in the nucleus, and DEGs of the extracellular fluid may lead to the discovery of unique signaling molecular mechanisms underlying EGFL8 function.

Microarray data permits the cataloging of a multitude of genes that are differentially expressed, and identifies nodes that are highly linked to the proteins regulated by EGFL8. Notably, a salient feature of the present study was that VEGF-A exhibited the highest degree of connectivity among all nodes in the gene network analysis of DEGs induced by EGFL8 and Angpt1 also exhibited a high degree of connectivity (1,867 connectivity). VEGF-A is the most well-characterized member of the VEGF family, being the most potent stimulator of angiogenic processes. ANGPT1 exhibits potent vascular protective effects and can repress VEGF-induced angiogenesis $(51,52)$.

These results were supported by DEG analysis in which VEGF-A expression was upregulated in EGFL8-silenced TECs and downregulated in EGFL8-overexpressing TECs, whereas Angpt1 expression was downregulated in EGFL8-silenced TECs and upregulated in EGFL8-overexpressing TECs. These findings provide compelling evidence that EGFL8 may play an important anti-angiogenic role. However, it is necessary to define the expression and function of EGFL8 in various processes of angiogenesis or vasculogenesis.

The activity of EGFL8 through autocrine or paracrine mechanism in TECs and other cell types remains uncertain. However, structural analysis of the EGFL8 protein predicted that it is secretory (18). In a previous study by the authors, to investigate the functional role of EGFL8 in TECs, TECs 


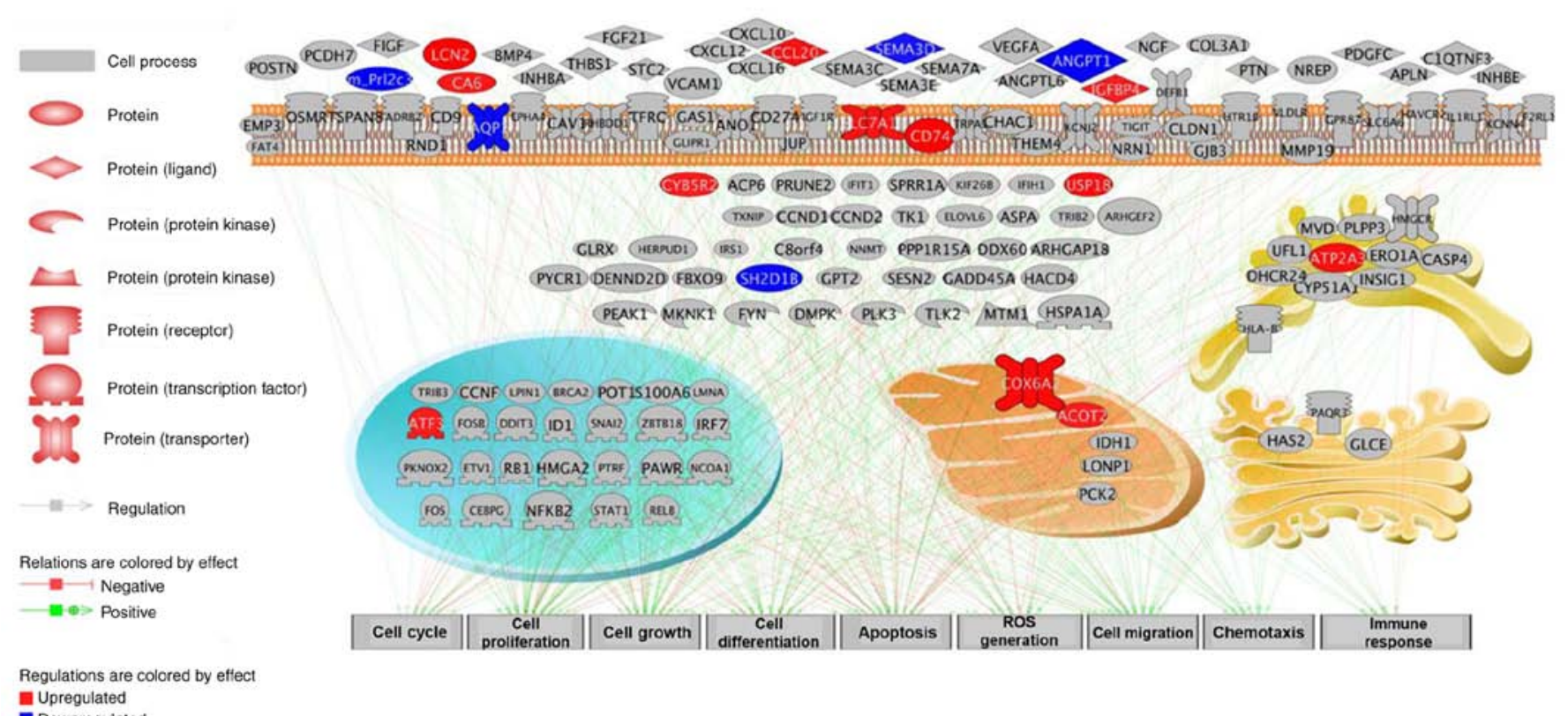

Figure 10. Proposed biological network of EGFL8-associated DEGs. A schematic representation of upregulated (red) and downregulated (blue) genes that share links within the DEGs is shown. EGFL8, epidermal growth factor-like domain 8; DEGs, differentially expressed genes.

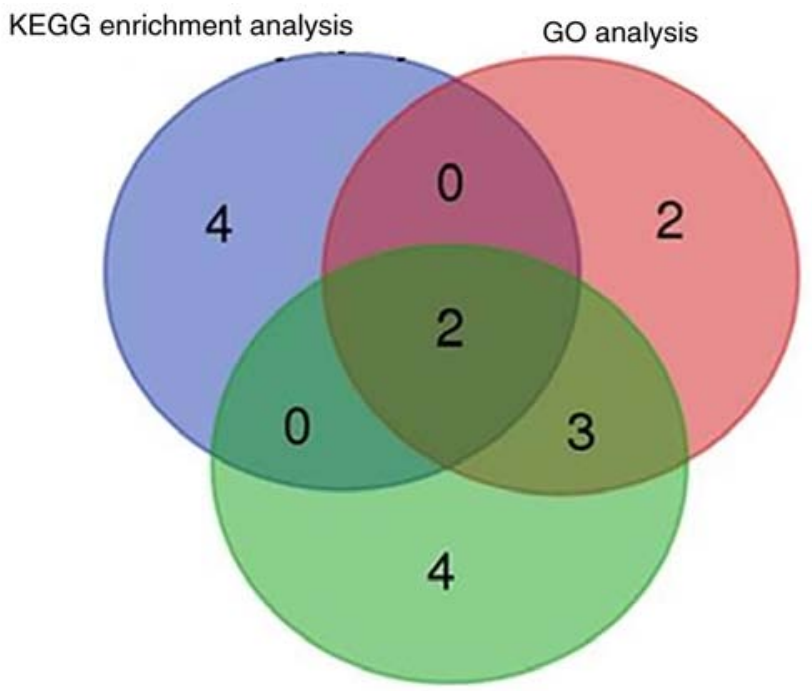

Pathway studio analysis

Figure 11. Comparison of 3 enrichment analyses showing overlapping enrichment for the pathways related to cell cycle and immune response.

were transfected with an EGFL8-expressing vector to overexpress EGFL8 protein and with an EGFL8 siRNA to knockdown EGFL8 expression (22). EGFL8-silenced TECs exhibited a significant increase in the number of adherent thymocytes by enhancing the expression of ICAM-1, while the overexpression of EGFL8 inhibited the adherence of TECs to thymocytes by suppressing ICAM-1 expression (22). Furthermore, in vitro co-culture experiments revealed that EGFL8 knockdown facilitated the maturation of thymocytes to $\mathrm{CD}^{+}$and $\mathrm{CD} 8^{+}$single-positive populations (22). These regulatory effects of EGFL8 in T cell development were further confirmed by the results that EGFL8 knockdown enhanced the expression of genes involved in thymopoiesis, such as IL-7, GM-CSF, and thymus-expressed chemokine (TECK). These data indicate that EGFL8 exerts inhibitory effects on TECs and thymocytes, suggesting that EGFL8 is a secreted protein and possibly modulates gene expression via a paracrine, autocrine or both mechanism(s). In addition, it was reported that, in an in vitro study, recombinant EGFL8 (rEGFL8) protein inhibited thymocyte proliferation and induced apoptosis and, in an in vivo study, rEGFL8 injection into mice resulted in a decreased thymic mass, and total number of thymocytes (23).

In conclusion, the ability to manipulate the activity of TECs is important for deciphering the underlying mechanisms governing $\mathrm{T}$ cell development, and developing approaches to regenerate the thymus after thymic involution induced by age, ablative therapies, or viral infection to boost new $\mathrm{T}$ cell production. The present study demonstrated that EGFL8 inhibited the proliferation of cTECs and provides new insight into its underlying molecular mechanisms. Furthermore, gene expression profiling of cTECs by the overexpression or silencing of EGFL8 led us to identify molecular signatures associated with the function of EGFL8 gene. The microarray results suggested that EGFL8 may be implicated in diverse cellular processes in cTECs (Fig. 13). A strong associatoin was found between EGFL8-associated genes and diverse physiological processes, including cell cycle, proliferation, growth, migration, and differentiation, as well as apoptosis, ROS generation, chemotaxis, and immune responses. Additionally, VEGF-A acts as a pivotal hub among genes connected with EGFL8. Therefore, the data obtained from the present study strongly suggests that EGFL8 functions as a regulator of various important physiologic processes in cTECs, and during angiogenesis. Further studies on the roles of the identified genes are necessary to understand the molecular mechanisms underlying EGFL8-mediated cell behavior. 

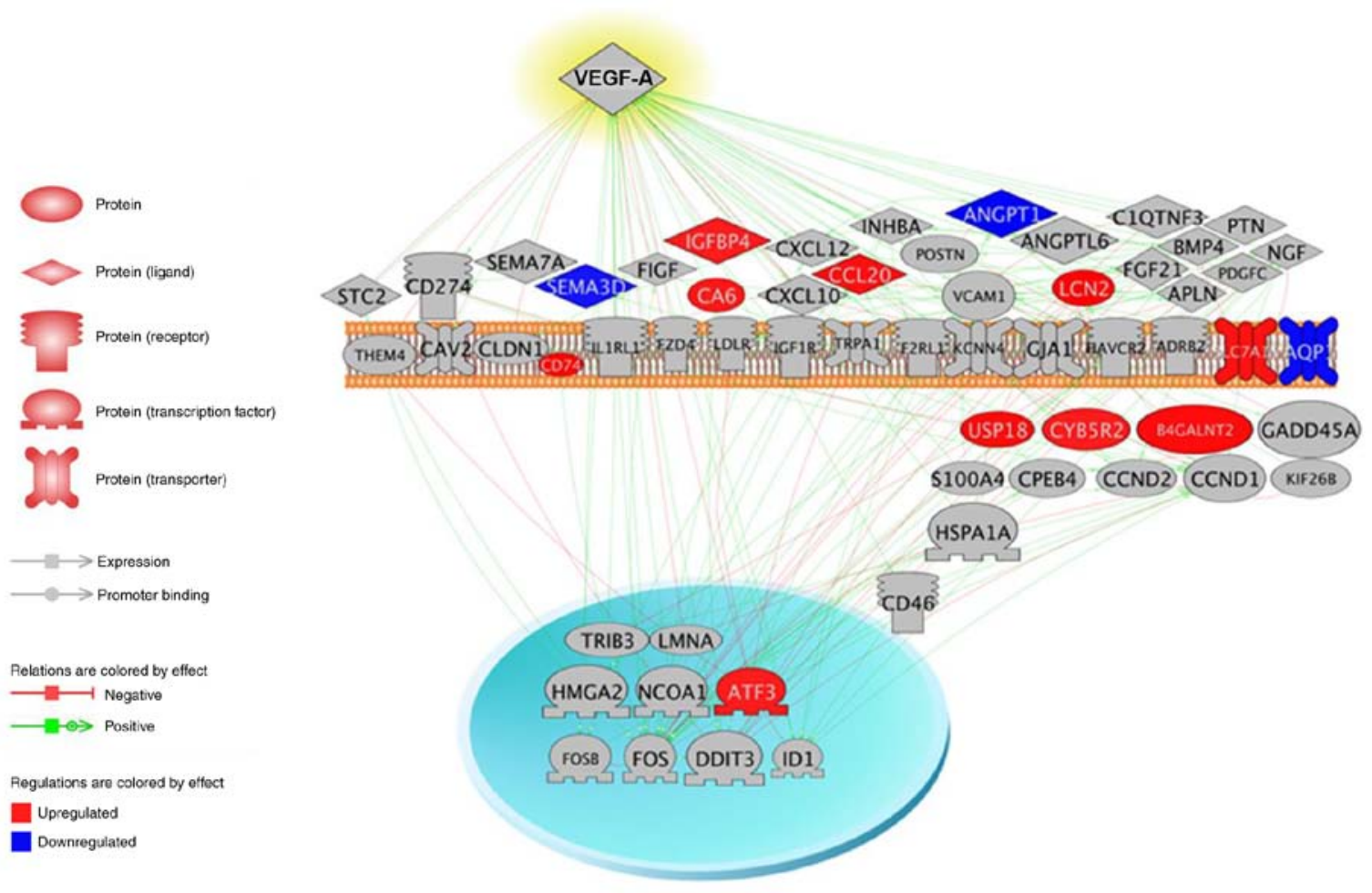

Figure 12. Proposed protein relations among proteins encoded by EGFL8 and VEGF-A. A schematic representation of the connectivity is shown where upregulation is depicted in red and downregulation is depicted in blue.

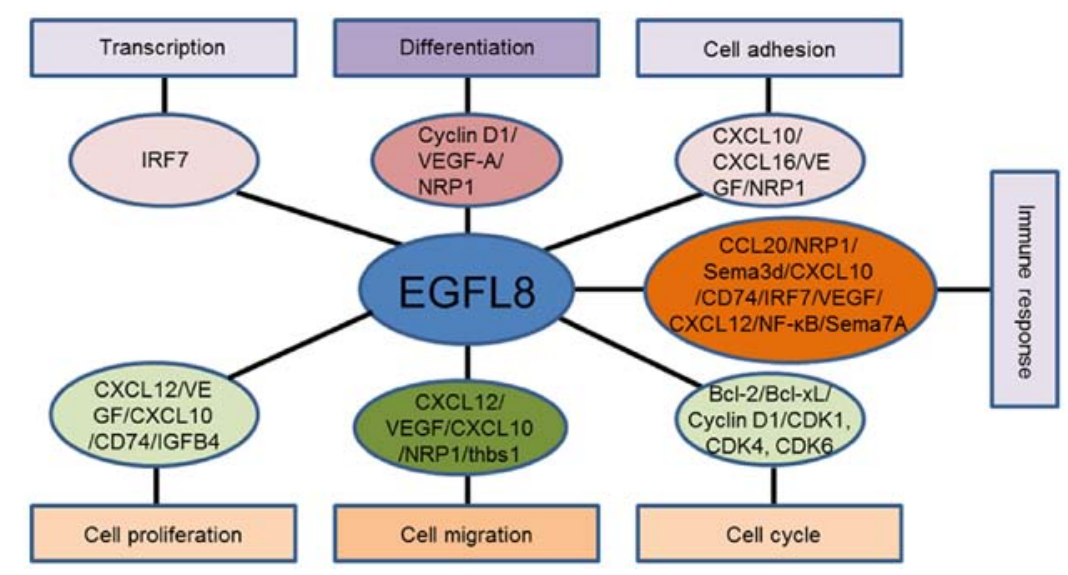

Figure 13. Molecular targets of EGFL8 and their potential functions. EGFL8 may be involved in the regulation of immune responses, cell cycle, cell growth, differentiation, adhesion, migration, proliferation, and transcription regulation via modulation of the expression of diverse genes essential for cellular functions.

\section{Acknowledgements}

Not applicable.

\section{Funding}

The present study was supported by the National Research Foundation of Korea (NRF) grant funded by the Korean government (MEST) (no. 2020R1A2C1004529).

\section{Availability of data and materials}

The datasets used and/or analyzed during the current study are available from the corresponding author on reasonable request.

\section{Authors' contributions}

YSL, DYL, YM and SY contributed to the conception and design of the study. YSL, DYL, HYK, YO and SH performed all experiments and verified the analytical data. YM contributed to the interpretation of the results. SY supervised the experiments in discussion with YSL, DYL, YO and SH. YSL, DYL and SY wrote the manuscript. YSL contributed to the revision of the manuscript. All authors discussed the final results and approved the final manuscript.

\section{Ethics approval and consent to participate}

Not applicable. 


\section{Patient consent for publication}

Not applicable.

\section{Competing interests}

The authors declare that they have no competing interests.

\section{References}

1. Hun M, Barsanti M, Wong K, Ramshaw J, Werkmeister J and Chidgey AP: Native thymic extracellular matrix improves in vivo thymic organoid T cell output, and drives in vitro thymic epithelial cell differentiation. Biomaterials 118: 1-15, 2017.

2. Tajima A, Pradhan I, Trucco M and Fan Y: Restoration of thymus function with bioengineered thymus organoids. Curr Stem Cell Rep 2: 128-139, 2016.

3. Andrew D and Aspinall R: Age-Associated thymic atrophy is linked to a decline in IL-7 production. Exp Gerontol 37: 455-463, 2002.

4. Yoon S, Yoo YH, Kim BS and Kim JJ: Ultrastructural alterations of the cortical epithelial cells of the rat thymus after cyclophosphamide treatment. Histol Histopathol 12: 401-413, 1997.

5. Yoon S, Lee HW, Baek SY, Kim BS, Kim JB and Lee SA: Upregulation of TrkA neurotrophin receptor expression in the thymic subcapsular, paraseptal, perivascular, and cortical epithelial cells during thymus regeneration. Histochem Cell Biol 119: $55-68,2003$.

6. Lee HW, Kim BS, Kim HJ, Lee CW, Yoo HJ, Kim JB and Yoon S: Upregulation of receptor activator of nuclear factor-kappaB ligand expression in the thymic subcapsular, paraseptal, perivascular, and medullary epithelial cells during thymus regeneration. Histochem Cell Biol 123: 491-500, 2005.

7. Lee HW, Kim SM, Shim NR, Bae SK, Jung IG, Kwak JY, Kim BS, Kim JB, Moon JO, Chung JS and Yoon S: Expression of nerve growth factor is upregulated in the rat thymic epithelial cells during thymus regeneration following acute thymic involution. Regul Pept 141: 86-95, 2007.

8. Park HJ, Kim MN, Kim JG, Bae YH, Bae MK, Wee HJ, Kim TW, Kim BS, Kim JB, Bae SK and Yoon S: Up-Regulation of VEGF expression by NGF that enhances reparative angiogenesis during thymic regeneration in adult rat. Biochim Biophys Acta 1773: 1462-1472, 2007

9. Kim YM, Kim HK, Kim HJ, Lee HW, Ju SA, Choi BK, Kwon BS Kim BS, Kim JB, Lim YT and Yoon S: Expression of 4-1BB and 4-1BBL in thymocytes during thymus regeneration. Exp Mol Med 41: 896-911, 2009.

10. Awong G, LaMotte-Mohs R and Zúñiga-Pflücker JC: Key players for T-cell regeneration. Curr Opin Hematol 17: 327-332, 2010.

11. Boehm T and Swann JB: Thymus involution and regeneration: Two sides of the same coin? Nat Rev Immunol 13: 831-838, 2013

12. Downing AK, Knott V, Werner JM, Cardy CM, Campbell ID and Handford PA: Solution structure of a pair of calcium-binding epidermal growth factor-like domains: Implications for the marfan syndrome and other genetic disorders. Cell 85: 597-605, 1996.

13. Hohenester E and Engel J: Domain structure and organisation in extracellular matrix proteins. Matrix Biol 21: 115-128, 2002.

14. Takahama Y: Journey through the thymus: Stromal guides for T-cell development and selection. Nat Rev Immunol 6: 127-135, 2006

15. Koeppe JR, Beach MA, Baerga-Ortiz A, Kerns SJ and Komives EA: Mutations in the fourth EGF-like domain affect thrombomodulin-induced changes in the active site of thrombin. Biochemistry 47: 10933-10939, 2008.

16. Singh AB and Harris RC: Autocrine, paracrine and juxtacrine signaling by EGFR ligands. Cell Signal 17: 1183-1193, 2005.

17. Chim SM, Tickner J, Chow ST, Kuek V, Guo B, Zhang G, Rosen V, Erber W and Xu J: Angiogenic factors in bone local environment. Cytokine Growth Factor Rev 24: 297-310, 2013.

18. Chim SM, Qin A, Tickner J, Pavlos N, Davey T, Wang H, Guo Y, Zheng MH and Xu J: EGFL6 promotes endothelial cell migration and angiogenesis through the activation of extracellular signal-regulated kinase. J Biol Chem 286: 22035-22046, 2011.

19. Fitch MJ, Campagnolo L, Kuhnert F and Stuhlmann H: Egfl7, a novel epidermal growth factor-domain gene expressed in endothelial cells. Dev Dyn 230: 316-324, 2004.
20. Wu F, Shirahata A, Sakuraba K, Kitamura Y, Goto T, Saito M, Ishibashi K, Kigawa G, Nemoto H, Sanada Y and Hibi K: Down-Regulation of EGFL8: A novel biomarker for advanced gastric cancer. Anticancer Res 31: 3377-3380, 2011.

21. Wu F, Shirahata A, Sakuraba K, Kitamura Y, Goto T, Saito M, Ishibashi K, Kigawa G, Nemoto H, Sanada Y and Hibi K: Down-Regulation of EGFL8: A novel prognostic biomarker for patients with colorectal cancer. Anticancer Res 31: 2249-2254, 2011

22. Choi HJ, Yoon TD, Muhammad I, Jeong MH, Lee J, Baek SY, Kim BS and Yoon S: Regulatory role of mouse epidermal growth factor-like protein 8 in thymic epithelial cells. Biochem Biophys Res Commun 425: 250-255, 2012.

23. Subhan F, Yoon TD, Choi HJ, Muhammad I, Lee J, Hong C, Oh SO, Baek SY, Kim BS and Yoon S: Epidermal growth factor-like domain 8 inhibits the survival and proliferation of mouse thymocytes. Int J Mol Med 32: 952-958, 2013.

24. Faas SJ, Rothstein JL, Kreider BL, Rovera G and Knowles BB: Phenotypically diverse mouse thymic stromal cell lines which induce proliferation and differentiation of hematopoietic cells. Eur J Immunol 23: 1201-1214, 1993

25. Irizarry RA, Hobbs B, Collin F, Beazer-Barclay YD, Antonellis KJ, Scherf U and Speed TP: Exploration, normalization, and summaries of high density oligonucleotide array probe level data. Biostatistics 4: 249-264, 2003.

26. Gentleman RC, Carey VJ, Bates DM, Bolstad B, Dettling M, Dudoit S, Ellis B, Gautier L, Ge Y, Gentry J, et al: Bioconductor: Open software development for computational biology and bioinformatics. Genome Biol 5: R80, 2004.

27. Eisen MB, Spellman PT, Brown PO and Botstein D: Cluster analysis and display of genome-wide expression patterns. Proc Natl Acad Sci USA 95: 14863-14868, 1998.

28. Sherman BT, Huang da W, Tan Q, Guo Y, Bour S, Liu D, Stephens R, Baseler MW, Lane HC and Lempicki RA: DAVID Knowledgebase: A gene-centered database integrating heterogeneous gene annotation resources to facilitate high-throughput gene functional analysis. BMC Bioinformatics 8: 426, 2007.

29. Yuryev A, Mulyukov Z, Kotelnikova E, Maslov S, Egorov S, Nikitin A, Daraselia N and Mazo I: Automatic pathway building in biological association networks. BMC Bioinformatics 7: 171, 2006.

30. Shakib S, Desanti GE, Jenkinson WE, Parnell SM, Jenkinson EJ and Anderson G: Checkpoints in the development of thymic cortical epithelial cells. J Immunol 182: 130-137, 2009.

31. Suzuki I, Martin S, Boursalian TE, Beers C and Fink PJ: Fas ligand costimulates the in vivo proliferation of CD81+ T Cells. Immunol 165: 5537-5543, 2000.

32. Rethi B, Vivar N, Sammicheli S, Fluur C, Ruffin N, Atlas A, Rajnavolgyi $\mathrm{E}$ and Chiodi F: Priming of $\mathrm{T}$ cells to fas-mediated proliferative signals by interleukin-7. Blood 112: 1195-1204, 2008.

33. Geretti E, Shimizu A and Klagsbrun M: Neuropilin structure governs VEGF and semaphorin binding and regulates angiogenesis. Angiogenesis 11: 31-39, 2008.

34. Sakurai A, Doçi CL and Gutkind JS: Semaphorin signaling in angiogenesis, lymphangiogenesis and cancer. Cell Res 22: 23-32, 2012.

35. Takahashi K, Ishida M, Hirokawa K and Takahashi H: Expression of the semaphorins sema 3D and sema 3F in the developing parathyroid and thymus. Dev Dyn 237: 1699-1708, 2008.

36. Mine T, Harada K, Matsumoto T, Yamana H, Shirouzu K, Itoh K and Yamada A: CDw108 expression during T-cell development. Tissue Antigens 55: 429-436, 2000.

37. Corbel C, Lemarchandel V, Thomas-Vaslin V, Pelus AS, Agboton C and Roméo PH: Neuropilin 1 and CD25 co-regulation during early murine thymic differentiation. Dev Comp Immunol 31: 1082-1094, 2007.

38. Olson TS and Ley K: Chemokines and chemokine receptors in leukocyte trafficking. Am J Physiol Regul Integr Comp Physiol 283: R7-R28, 2002

39. Ying S, O'Connor B, Ratoff J, Meng Q, Mallett K, Cousins D, Robinson D, Zhang G, Zhao J, Lee TH and Corrigan C: Thymic stromal lymphopoietin expression is increased in asthmatic airways and correlates with expression of Th2-attracting chemokines and disease severity. J Immunol 174: 8183-8190, 2005.

40. Heydtmann M, Lalor PF, Eksteen JA, Hübscher SG, Briskin M and Adams DH: CXC chemokine ligand 16 promotes integrin-mediated adhesion of liver-infiltrating lymphocytes to cholangiocytes and hepatocytes within the inflamed human liverl. Immunol 174: 1055-1062, 2005 
41. Cowan JE, Baik S, McCarthy NI, Parnell SM, White AJ, Jenkinson WE and Anderson G: Aire controls the recirculation of murine Foxp $3^{+}$regulatory T-cells back to the thymus. Eur J Immunol 48: 844-854, 2018.

42. Rivino L, Gruarin P, Häringer B, Steinfelder S, Lozza L, Steckel B, Weick A, Sugliano E, Jarrossay D, Kühl AA, et al: CCR6 is expressed on an IL-10-producing, autoreactive memory $\mathrm{T}$ cell population with context-dependent regulatory function. J Exp Med 207: 565-577, 2010.

43. Balamayooran G, Batra S, Cai S, Mei J, Worthen GS, Penn AL and Jeyaseelan S: Role of CXCL5 in leukocyte recruitment to the lungs during secondhand smoke exposure. Am J Respir Cell Mol Biol 47: 104-111, 2012.

44. Yan Q, Jiang L, Liu M, Yu D, Zhang Y, Li Y, Fang S, Li Y, Zhu YH, Yuan YF and Guan XY: ANGPTL1 interacts with integrin $\alpha 1 \beta 1$ to suppress HCC angiogenesis and metastasis by inhibiting JAK2/STAT3 signaling. Cancer Res 77: 5831-5845, 2017.

45. Leng L, Metz CN, Fang Y, Xu J, Donnelly S, Baugh J, Delohery T, Chen Y, Mitchell RA and Bucala R: MIF signal transduction initiated by binding to CD74. J Exp Med 197: 1467-1476, 2003.

46. Abu El-Asrar AM, Ahmad A, Siddiquei MM, De Zutter A Allegaert E, Gikandi PW, De Hertogh G, Van Damme J, Opdenakker G and Struyf S: The proinflammatory and proangiogenic macrophage migration inhibitory factor is a potential regulator in proliferative diabetic retinopathy. Front Immunol 10: $2752,2019$.

47. Shibata A, Nagaya T, Imai T, Funahashi H, Nakao A and Seo H: Inhibition of NF-kappaB activity decreases the VEGF mRNA expression in MDA-MB-231 breast cancer cells. Breast Cancer Res Treat 73: 237-243, 2002.
48. Laursen LS, Overgaard MT, Søe R, Boldt HB, Sottrup-Jensen L, Giudice LC, Conover CA and Oxvig C: Pregnancy-Associated plasma protein-A (PAPP-A) cleaves insulin-like growth factor binding protein (IGFBP)-5 independent of IGF: Implications for the mechanism of IGFBP-4 proteolysis by PAPP-A. FEBS Lett 504: 36-40, 2001

49. Vacca A, Di Marcotullio L, Giannini G, Farina M, Scarpa S, Stoppacciaro A, Calce A, Maroder M, Frati L, Screpanti I and Gulino A: Thrombospondin-1 is a mediator of the neurotypic differentiation induced by EGF in thymic epithelial cells. Exp Cell Res 248: 79-86, 1999.

50. Otero DC, Baker DP and David M: IRF7-Dependent IFN- $\beta$ production in response to RANKL promotes medullary thymic epithelial cell development. J Immunol 190: 3289-3298, 2013.

51. Chinoy MR, Graybill MM, Miller SA, Lang CM and Kauffman GL: Angiopoietin-1 and VEGF in vascular development and angiogenesis in hypoplastic lungs. Am J Physiol Lung Cell Mol Physiol 283: L60-L66, 2002.

52. Fagiani E1, Lorentz P, Kopfstein L and Christofori G: Angiopoietin-1 and -2 exert antagonistic functions in tumor angiogenesis, yet both induce lymphangiogenesis. Cancer Res 71: 5717-5727, 2011.

This work is licensed under a Creative Commons Attribution-NonCommercial-NoDerivatives 4.0 International (CC BY-NC-ND 4.0) License. 